\title{
The Electoral Consequences of Cellphone Coverage Expansion
}

\author{
Shuning Ge* Guy Grossman ${ }^{\dagger} \quad$ Katrina Kosec $^{\ddagger} \quad$ Apoorva Lal $^{\S}$ \\ Benjamin Laughlin ${ }^{\text {Il }}$
}

February 1, 2023

\begin{abstract}
Using the case of Ghana, we analyze the electoral effects of cellphone coverage expansion in a developing country setting. We construct constituencylevel panel data of electoral results for Ghana's six general elections during 1996-2016 and combine these with high-resolution geocoded annual coverage information using a difference-in-differences design. We find that cellphone coverage benefited incumbents in both presidential and parliamentary elections. This effect appears to be due to cellphone coverage expansion improving both citizens' wealth and faith in the economy as opposed to general perceptions of government performance, political knowledge, or votebuying. The results highlight the potential for even basic information and communications technologies to make retrospective voting more common in settings where ethnic voting, clientelism, and vote-buying are common.
\end{abstract}

Word Count: 3987

\footnotetext{
*Senior Data Research Coordinator, University of Pennsylvania. Email: shuningg@sas.upenn.edu.

${ }^{\dagger}$ Professor, University of Pennsylvania. Email: ggros@upenn.edu.

‡Senior Research Fellow, International Food Policy Research Institute; Lecturer, Johns Hopkins University. Email: kkosec1@jhu.edu.

§PhD Candidate, Stanford University. Email: apoorval@stanford.edu.

II Assistant Professor, New York University Abu Dhabi. Email: benjamin.laughlin@nyu.edu.

"We gratefully acknowledge insightful comments and support from Kwaw Andam, Sarah Brierley, Nahomi Ichino, Noah Nathan, George Ofosu, Pedro Vicente, and Jens Hainmueller. We also thank Paul Heysch de la Borde for excellent research assistance. All remaining errors are our own. We would like to thank all funders who supported this research through their contributions to the CGIAR Trust Fund: https:/ /www.cgiar.org/funders/. The research was also supported by the School of Arts and Science's Global Inquires grant at the University of Pennsylvania.
} 


\section{Introduction}

Does cellphone coverage affect voting behavior in developing countries; and if so - through which channels? On the one hand, cellphones can expand economic opportunities (Mensah, 2021). This may spur retrospective voting, thereby benefiting the incumbent party. On the other hand, cellphones may improve political knowledge and voter coordination (Guriev, Melnikov, and Zhuravskaya, 2021), facilitate voter mobilization by political parties or brokers, and increase pressure (from one's social network) to vote. These alternative channels do not a-priori advantage incumbent relative to opposition parties. It is therefore unclear, ex-ante, whether and how the dramatic expansion of cellular technologies in the past two decades affects aggregate electoral outcomes.

A growing body of work has explored the socio-economic consequences of cellphone penetration, finding it can raise incomes and improve welfare in low-income countries. Cellphones increase farmers' incomes by improving productivity (Gupta, Ponticelli, and Tesei, 2020; Cole and Fernando, 2021), and by reducing information asymmetries between buyers and smallholder sellers (Aker, 2010) as well as price dispersion across markets (Jensen, 2007; Aker and Fafchamps, 2015). In more urban settings, cellphone penetration has been associated with increased productivity (Hjort and Poulsen, 2019). Additionally, it can help individuals cope with economic shocks (Jack and Suri, 2014), and reduce infant mortality (Mensah, Tafere, and Abay, 2022). Improved socio-economic conditions should, on average, benefit the incumbent government (Duch and Stevenson, 2006).

A parallel literature has explored the relationship between cellphone coverage penetration and contentious politics. By lowering both coordination and information costs, cellphone coverage has been shown to increase protest (Christensen and Garfias, 2018), mass mobilization (Manacorda and Tesei, 2020) and, under certain conditions, violent conflict (Pierskalla and Hollenbach, 2013; Shapiro and Siegel, 2015). Especially in countries with weak electoral institutions, improved collective action capacity and lower information costs should generally benefit opposition parties (Arias et al., 2019).

However, we know of almost no evidence on whether or how cellphone coverage affects voting behavior in developing country settings. As access to cellphones continues to expand 
rapidly, especially in developing countries where saturation points have not yet been reached (Kosec and Wantchekon, 2020), understanding their implications for electoral outcomes is critical for both theory and policy.

We address this gap by providing novel evidence on the relationship between cellphone coverage and aggregate voting outcomes in Ghana. We construct a panel dataset of cellphone coverage at the local level using high-resolution annual coverage maps and combine it with constituency-level voting records from six presidential and parliamentary elections (spanning 1996 to 2016). Ghana is a useful case given that elections are highly competitive, resulting in alteration of power between the two main political parties-the New Patriotic Party (NPP) and the National Democratic Congress (NDC). Thus, unlike some proximate countries such as Uganda and Tanzania, the presence of competitive elections in which the party of the incumbent is changing over time offers a cleaner test of the relationship between cellphone coverage and incumbent support.

Since spatial variation in cellphone coverage could be correlated with unobserved determinants of electoral outcomes, we use a difference-in-differences (DiD) design. Specifically, we use within-constituency changes in coverage over time to test how well elected incumbentsboth the president and members of Parliament (MPs) — fare in subsequent elections, as a function of increases in cellphone coverage. We find that increased cellphone coverage predicts increased vote shares for incumbents in both parliamentary and presidential elections, but no changes in voter turnout.

We then assess the mechanisms accounting for these results-considering whether voters respond to changes in the information environment or engage in retrospective voting stimulated by economic benefits conferred by cellphones. We find most support for the latter explanation; increased cellphone coverage is associated with significant increases in wealth along with perceptions that the economy is doing well and that economic policy benefits the Ghanaian people. By contrast, we find no evidence that cellphone coverage changed general perceptions of government performance, political knowledge, or vote-buying.

We make four main contributions to the literature. First, we offer unique evidence on the effects of cellphone coverage on voting behavior in a lower-middle-income country setting. Specifically, we complement two existing studies which estimate the effects of a different com- 
munication technology (3G internet access) in richer countries, and with a focus on a different set of mechanisms. Guriev, Melnikov, and Zhuravskaya (2021) find that 3G expansion in Europe lowered vote shares for incumbent parties and increased support for populist parties. Donati (2022) finds that 3G access in South Africa increased voter turnout and the number of parties running, and lowered the vote share of the ruling party. Both of these papers focus on the Internet's effects on polarization and the media landscape as mechanisms. Instead, our focus is on a more basic form of mobile technology, largely limited to phone calls, text messages, and rudimentary internet access. Moreover, we advance the literature by considering incomes and the health of the economy as mediating factors.

Second, we contribute to debates about whether retrospective voting-the idea that citizens reward the government for good economic outcomes and punish it for bad ones-takes place in developing countries. Given that political parties in many developing countries are not programmatic, and given relatively low levels of political knowledge, identity plays an oversized role in explaining voting behavior. Thus, it has been argued that voters select candidates along ethnic lines with relatively limited attention to performance (Adida et al., 2017; Shockley and Gengler, 2020). Our study's findings are consistent with work suggesting that retrospective voting does affect at least some voters in developing country settings (Harding, 2015).

Third, we contribute to a broad literature on factors influencing voter attribution of credit for economic improvements (Sances, 2017; Healy, Kosec, and Mo, 2017; Benedictis-Kessner and Warshaw, 2020). Specifically, for the case of wealth-conferring technological improvements, we show that there is a relatively broad incumbency advantage.

Finally, our paper also relates to literature on the effects of cellphones on political outcomes other than voting, including the incidence of violent events (Warren, 2015; Weidmann, 2016), protest participation (Christensen and Garfias, 2018), contact with elected officials (Grossman, Humphreys, and Sacramone-Lutz, 2020), electoral fraud (Gonzalez, 2021), election monitoring (Callen et al., 2016), confidence in government (Gupta, Ponticelli, and Tesei, 2020), and national identification (Choi, Laughlin, and Schultz, 2021). 


\section{Context}

Ghana has a highly competitive presidential system with a unicameral parliament. During our study period (1996-2016), the number of seats in parliament grew from 200 to 275 . While clientelism is widespread (Brierley and Nathan, 2022) and electoral fraud and violence are at times present (Asunka et al., 2019), recent Ghanaian elections have been relatively free and fair (Brierley and Kramon, 2020).

Politics in Ghana is dominated by two main parties - the New Patriotic Party (NPP) and the National Democratic Congress (NDC) — which draw support based primarily on ethnic rather than programmatic appeals. Our study takes place in the context of numerous close general elections during 1996-2016; the party winning the presidency was the NDC in 1996 (in a single round), NPP in 2000 (two rounds), NPP in 2004 (single round), NDC in 2008 (two rounds), NDC in 2012 (single round), and NPP in 2016 (single round).

Notwithstanding its growing middle class, Ghana has been recently described as stuck in a trap of clientelism and ethnic voting (Nathan, 2019). Parties in many constituencies spur ethnic voting, engaging in exclusive forms of mobilization including narratives based on indigeneity (Klaus and Paller, 2017). Nonetheless, evaluations and perceptions of the parties themselves are important determinants of voting behavior in Ghana (Hoffman and Long, 2013).

A lower-middle-income country, Ghana has a diverse and rich resource base. GDP per capita was merely $\$ 389$ (current USD) in 1996, which rose to 1,900 by 2016 (World Bank, 2022), the last election we analyze. Amid this economic growth, cellphone coverage expanded rapidly but unevenly (from zero in 1996 to near saturation by 2016), as shown at the electoral constituency level in Figure 1. The pattern of expansion was broadly motivated by private sector profitseeking incentives. In Appendix C, we show that increases in cellphone coverage are associated with significantly greater household cellphone ownership (Table SI-4) and usage (Table SI-5). 
Figure 1: Cell-phone coverage expansion between 2000 and 2016 in Ghana

Coverage in 2000

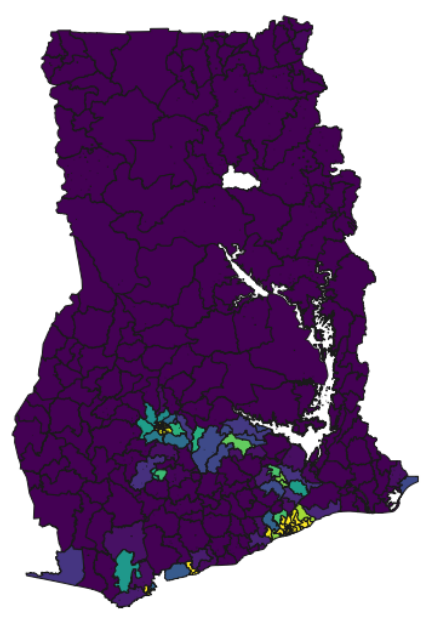

Coverage in 2012

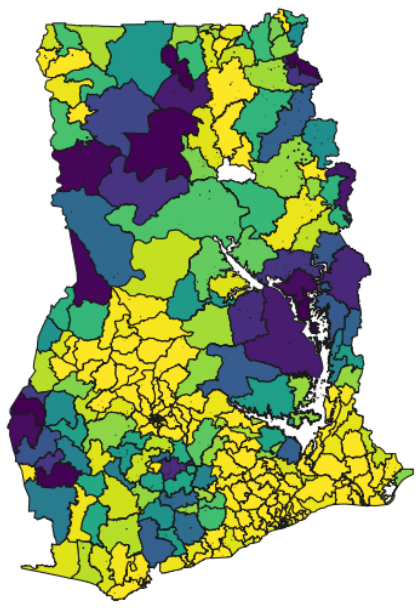

Coverage in 2004

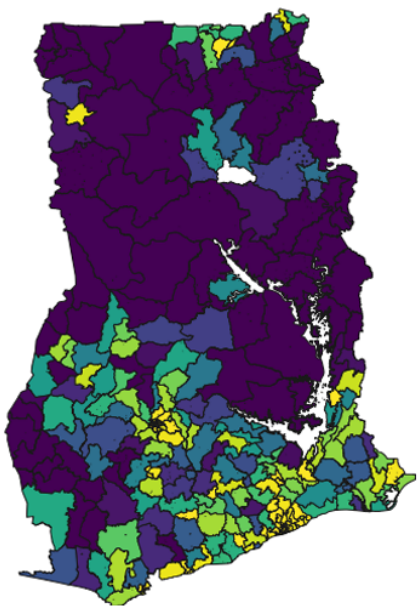

Coverage in 2016

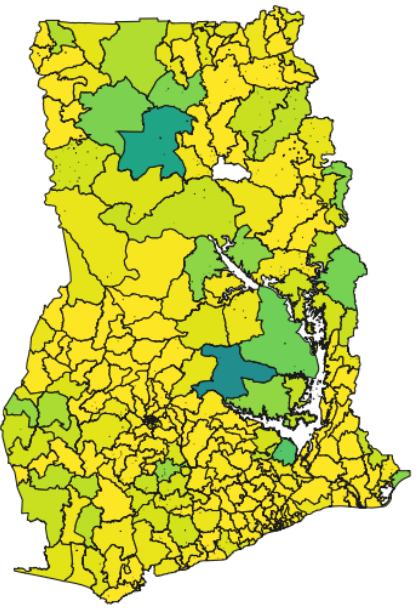

Coverage in 2008
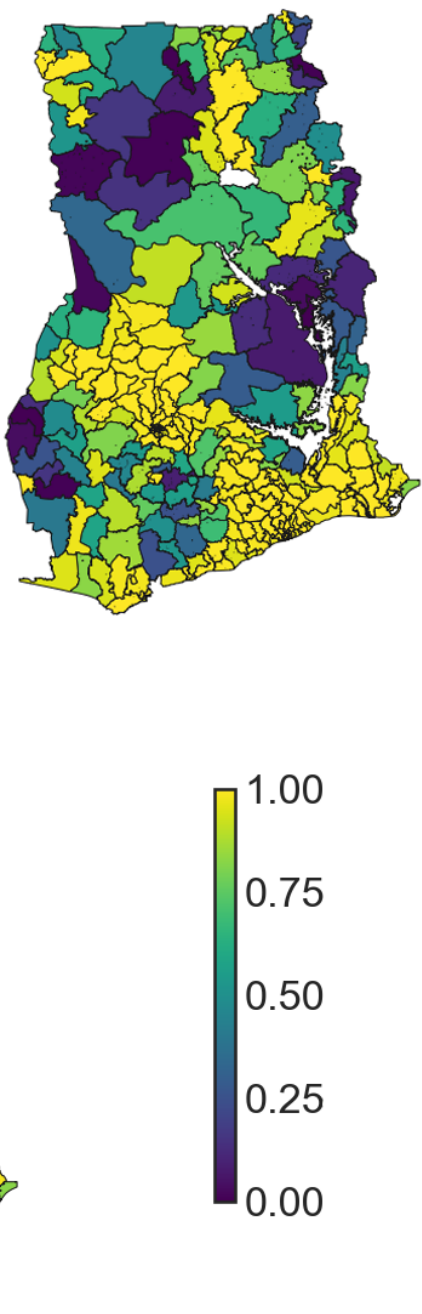

Notes: Each polygon is a parliamentary constituency. Color values represent the share of the population with cellphone coverage in each year. 


\section{Research Design}

\subsection{Data and variable description}

We construct a constituency-election year panel dataset of electoral results and cellphone coverage for the six elections between 1996 and 2016. The study's key dependent variables are incumbent vote share in both presidential and parliamentary elections, provided by the Electoral Commission of Ghana. Following conventional practice (e.g., Klašnja and Titiunik, 2017), when the incumbent does not stand for reelection, the dependent variable is the vote share of the incumbent party. We further analyze voter turnout in each election.

Ghana has created new constituencies over time, primarily by splitting existing constituencies in two. To construct a panel with stable constituency units across elections, we aggregate electoral results of split-off constituencies to 1996, the earliest constituency units.

We measure cellphone coverage by spatially merging coverage maps produced by the GSM Association (GSMA, 2019) with the smallest available census geometries (enumeration areas, henceforth EAs), which are then aggregated to the constituency level. While GSMA's measure of coverage is continuous, we also construct a binary treatment measure, defining a constituency as heavily covered when $50 \%$ or more of its population has coverage. ${ }^{1}$ Cellphone coverage increased from zero in 1996 to an average of $96.9 \%$ of the population in a constituency in 2016 (Table SI-1). The number of constituencies with over 50\% cellphone coverage increased from zero to 191 out of 193 constituencies over the same period.

We analyze the relationship between cellphone coverage and wealth (one possible mechanism) using two independent proxy measures. First, following Burke et al. (2021), we proxy local wealth with Night-time Light Density from a recently-published harmonized dataset (Li et al., 2020). Second, we construct a wealth index from the 2000 and 2010 Ghanaian censuses (an average of 11 indicator variables for durable assets present in the household). Table SI-1 presents descriptive statistics for our key electoral outcome measures, our cellphone coverage variable (treatment), and these wealth measures. Appendix A provides a detailed discussion of all variables' construction other than night-lights, which are described in Appendix F.

\footnotetext{
${ }^{1}$ We chose this threshold as it has a natural interpretation (individuals are more likely to have than not have cellphone coverage). In the SI, we demonstrate robustness of our findings to a higher threshold of $75 \%$ (Tables SI-13 and SI-14).
} 
Finally, we use Afrobarometer data from 1999 to 2015 to test additional potential mechanisms, described in detail in Appendix B and summarized in Table SI-2.

\subsection{Estimation}

We employ a differences in differences design that leverages within-constituency increases in cellphone coverage over time to identify its effects on electoral outcomes. We use the following specifications when analyzing election outcomes as well as in subsequent analysis of night-time light density:

$$
\begin{aligned}
& y_{i r t}=\tau \text { Coverage }_{i r t}+\delta_{i}+\gamma_{t}+\varepsilon_{i r t} \\
& y_{i r t}=\tau \text { Coverage }_{i r t}+\delta_{i}+\xi_{r t}+\varepsilon_{i r t} \\
& y_{i r t}=\tau \text { Coverage }_{i r t}+\delta_{i}+\delta_{i} t+\xi_{r t}+\varepsilon_{i r t}
\end{aligned}
$$

where $i$ indexes constituencies, ${ }^{2} r$ indexes regions (groupings of constituencies), and $t$ indexes elections. $y_{i r t}$ is an electoral outcome (incumbent vote share or turnout in the parliamentary or presidential election) and Coverage ${ }_{i r t} \in[0,1]^{3}$ is the population-weighted cellphone coverage in constituency $i$ in election $t$, described in sub-section 3.1.

Eqn 1 is a standard two-way fixed effects regression that partials out the effects of timeinvariant constituency specific confounders $\delta_{i}$ and uniform election shocks $\gamma_{t}$ and yields consistent estimates as long as parallel trends hold conditional on these fixed effects. However, this specification may yield biased estimates in the presence of time-varying constituency-specific confounders, such as regional electoral swings in favor of particular parties. Eqn 2 addresses this by incorporating region $\times$ election fixed effects, which account for region-level electoral shocks. Eqn 3, further adds constituency-level linear time trends, which identifies the treatment effect of coverage from departures from constituency-level trends in political outcomes.

We also conservatively control for potentially non-linear trends in constituency characteristics known to predict voting behavior, derived from the 2000 census. Specifically, we use our wealth index and two variables capturing the shares of the population from ethnic groups likely

\footnotetext{
${ }^{2}$ In our analysis of night-time light density, $i$ indexes EAs.

${ }^{3}$ Since the treatment is continuously distributed, we estimate an average derivative when using linear regression; we evaluate the suitability of this linear approximation in Appendix D.2.
} 
to support the NPP (specifically, Akan, other than the Fante subgroup) and the NDC (specifically, Fante, Ewe, Ga-Dangme, Mole-Dagbani, Gonja, Kokomba, Hausa) (Brierley, 2021, p. 10). These covariates are interacted with year indicators.

Additional analyses of potential causal mechanisms use Afrobarometer (AB) data on wealth, perceptions of the economy, vote-buying, perceptions of government performance, and political knowledge. As these comprise repeated cross-sections of individuals and not panel data, we estimate the following equation:

$$
y_{i t}=\alpha \text { Coverage }_{i t}+\zeta \boldsymbol{Z}_{i t}+\theta_{t}+\varepsilon_{i t}
$$

where $i$ indexes respondents, $t$ indexes elections, and $\theta_{t}$ are year fixed effects. $Z_{i}$ comprises individual-level demographic and geo-spatial controls summarized in Table SI-2. We estimate specifications with and without additional EA-level pre-treatment covariates derived from the 2000 Ghanaian census, as described above.

\section{Results}

\subsection{Effects of cellphone coverage on electoral outcomes}

Increases in cellphone coverage predict higher incumbent vote shares for both types of elections. Table 1 presents results for presidential elections. Across specifications, we see a sizable, positive impact of expanded cellphone coverage on the vote share of the ruling presidential party (Panel A). Obtaining heavy cellphone coverage predicts between a 3.6 and 4.9 percentage point increase in the vote share of the incumbent party, depending on the model (columns 1-3, which correspond to Eqns 1-3, respectively). Further, our continuous measure of coverage reveals that a 1 standard deviation (S.D.) increase in cellphone coverage predicts a 2.7 to 3.6 percentage point increase in the vote share of the incumbent party (columns 4-6). These findings are statistically significant at conventional levels when we estimate Eqns 1 and 2, and are just under conventional significance levels when we estimate Eqn 3. Increased support for the incumbent president's party does not come from higher voter turnout (Panel B).

Table 2 presents parliamentary election results. Across all model specifications, having heavy 
Table 1: Presidential Election Results at the Constituency-Level

\begin{tabular}{|c|c|c|c|c|c|c|}
\hline \multicolumn{7}{|c|}{ Panel A: Incumbent Vote Share in Presidential election } \\
\hline & \multicolumn{3}{|c|}{ Discretized } & \multicolumn{3}{|c|}{ Continuous } \\
\hline & (1) & $(2)$ & (3) & $(4)$ & (5) & $(6)$ \\
\hline Cellphone Coverage & $\begin{array}{l}0.049 * * \\
(0.021)\end{array}$ & $\begin{array}{l}0.036^{* *} \\
(0.017)\end{array}$ & $\begin{array}{c}0.037 \\
(0.022)\end{array}$ & $\begin{array}{c}0.036^{* * *} \\
(0.013)\end{array}$ & $\begin{array}{l}0.025^{* *} \\
(0.012)\end{array}$ & $\begin{array}{c}0.027 \\
(0.017)\end{array}$ \\
\hline Observations & 1153 & 1153 & 1153 & 1153 & 1153 & 1153 \\
\hline$R^{2}$ & 0.62 & 0.82 & 0.82 & 0.62 & 0.82 & 0.82 \\
\hline \multicolumn{7}{|c|}{ Panel B: Turnout in Presidential election } \\
\hline & \multicolumn{3}{|c|}{ Discretized } & \multicolumn{3}{|c|}{ Continuous } \\
\hline & $(1)$ & $(2)$ & (3) & $(4)$ & $(5)$ & $(6)$ \\
\hline Cellphone Coverage & $\begin{array}{c}0.012 \\
(0.018)\end{array}$ & $\begin{array}{c}0.017 \\
(0.017)\end{array}$ & $\begin{array}{c}0.018 \\
(0.021)\end{array}$ & $\begin{array}{c}0.008 \\
(0.013)\end{array}$ & $\begin{array}{c}0.013 \\
(0.014)\end{array}$ & $\begin{array}{c}0.016 \\
(0.017)\end{array}$ \\
\hline Observations & 1153 & 1153 & 1153 & 1153 & 1153 & 1153 \\
\hline$R^{2}$ & 0.31 & 0.34 & 0.58 & 0.31 & 0.34 & 0.58 \\
\hline Year FE & Yes & No & No & Yes & No & No \\
\hline Region $\times$ Year FE & No & Yes & Yes & No & Yes & Yes \\
\hline Const. vary slope & No & No & Yes & No & No & Yes \\
\hline
\end{tabular}

Notes: This table presents estimates for presidential elections. The independent variable is dichotomous cellphone coverage measure in models (1)-(3) (which correspond to Eqns 1-3, respectively), and continuous in models (4)-(6) (which correspond to Eqns 1-3, respectively). All models include constituency-level 2000 census controls (a wealth index, and two variables capturing the shares of the population from ethnic groups likely to support the NPP and the NDC) interacted with year indicators, as well as constituency fixed effects. Const. stands for constituency. Const. vary slope indicates the presence of constituency-level time trends. Robust standard errors are shown in parentheses: ${ }^{* * *} p<0.01 ;{ }^{* *} p<0.05 ;{ }^{*} p<0.1$.

Data source: Electoral commission of Ghana and GSMA.

cellphone coverage predicts a statistically significant increase in the vote share of the incumbent MP (Panel A). We observe between a 2.3 and 2.9 percentage point increase in the vote share of the incumbent MP (columns 1-3). Further, a 1 S.D. increase in cellphone coverage predicts a 2.8 to 3.0 percentage point increase in the vote share of the incumbent party (columns 4-6). That point estimates remain similar in magnitude across specifications increases our confidence in the validity of our identifying assumptions. Once again, we find no evidence that increased cellphone coverage increases voter turnout (Table 2, panel B). 
Table 2: Parliamentary Election Results at the Constituency-Level

\begin{tabular}{|c|c|c|c|c|c|c|}
\hline \multicolumn{7}{|c|}{ Panel A: Incumbent Vote Share in Parliamentary election } \\
\hline & \multicolumn{3}{|c|}{ Discretized } & \multicolumn{3}{|c|}{ Continuous } \\
\hline & $(1)$ & $(2)$ & (3) & $(4)$ & (5) & $(6)$ \\
\hline Cellphone Coverage & $\begin{array}{c}0.029 * * * \\
(0.008)\end{array}$ & $\begin{array}{c}0.029 * * * \\
(0.009)\end{array}$ & $\begin{array}{l}0.023^{* *} \\
(0.010)\end{array}$ & $\begin{array}{c}0.029 * * * \\
(0.006)\end{array}$ & $\begin{array}{c}0.030 * * * \\
(0.006)\end{array}$ & $\begin{array}{c}0.028^{* * *} \\
(0.007)\end{array}$ \\
\hline Observations & 1167 & 1167 & 1167 & 1167 & 1167 & 1167 \\
\hline$R^{2}$ & 0.73 & 0.76 & 0.82 & 0.73 & 0.76 & 0.82 \\
\hline \multicolumn{7}{|c|}{ Panel B: Turnout in Parliamentary election } \\
\hline & \multicolumn{3}{|c|}{ Discretized } & \multicolumn{3}{|c|}{ Continuous } \\
\hline & $(1)$ & $(2)$ & (3) & $(4)$ & $(5)$ & $(6)$ \\
\hline Cellphone Coverage & $\begin{array}{c}0.002 \\
(0.012)\end{array}$ & $\begin{array}{c}0.011 \\
(0.011)\end{array}$ & $\begin{array}{c}0.011 \\
(0.013)\end{array}$ & $\begin{array}{c}0.008 \\
(0.013) \\
\end{array}$ & $\begin{array}{c}0.013 \\
(0.014)\end{array}$ & $\begin{array}{c}0.016 \\
(0.017)\end{array}$ \\
\hline Observations & 1168 & 1168 & 1168 & 1153 & 1153 & 1153 \\
\hline$R^{2}$ & 0.33 & 0.35 & 0.62 & 0.31 & 0.34 & 0.58 \\
\hline Year FE & Yes & No & No & Yes & No & No \\
\hline Region $\times$ Year FE & No & Yes & Yes & No & Yes & Yes \\
\hline Const. vary slope & No & No & Yes & No & No & Yes \\
\hline
\end{tabular}

Notes: This table presents estimates for parliamentary elections. All notes from Table 1 apply here as well. Data source: Electoral commission of Ghana and GSMA.

\subsection{Robustness and model assumptions}

Parallel trends are challenging to evaluate in our setting because: (1) cellphone coverage treatment is continuous and (2) our sample includes only one pre-treatment period (1996). Nevertheless, we can analyze whether coverage was strategically expanded to constituencies favoring the incumbent by regressing past electoral outcomes on contemporaneous cellphone coverage. As Appendix D.1 shows, we find limited evidence of such targeting (Table SI-6).

In Appendix D.2, we evaluate the appropriateness of using linear regressions for a continuous treatment. We employ a test of parametric functional form and find that this specification adequately captures the relationship between cellphone coverage expansion and political outcomes. Next, in Appendix D.3, we analyze whether electoral outcomes in year $t$ that we attribute to cellphone coverage expansion in that year are in fact due to previous expansions in cellphone coverage. If this were the case, it would invalidate the "no carry-over" assumption 
required of our model. We find little evidence that this is the case, with small point estimates and broadly null effects (Tables SI-7 and SI-8).

We also show robustness to omitting 2000 census controls interacted with year dummies (see Tables SI-9 and SI-10; indeed, our results prove stronger without these flexible controls) and to using $75 \%$ of the population rather than $50 \%$ as the cutoff indicating heavy cellphone coverage (see Tables SI-13-SI-12).

Finally, since cellphone rollout is staggered across the country, one might be concerned about time heterogeneity bias produced by staggered adoption (Goodman-Bacon, 2021). While Eqn 3 partially accounts for this by incorporating region-year intercepts that restrict comparisons to within the same region and election, we encouragingly obtain similar estimates from a fixed effects imputation estimator that is robust to heterogeneous effects (Liu, Wang, and $\mathrm{Xu}, 2021$ ), detailed in Appendix E.1 (Figure SI-3).

\section{Mechanisms}

We consider two potential mechanisms by which cellphone coverage may affect incumbent vote share: retrospective voting and informational advantages. If retrospective voting is central in explaining incumbency advantages, we would expect increases in cellphone coverage to predict increases in households' wealth, but also that households update their perception of the health of the economy. We might also expect decreases in vote-buying, as incumbents may perceive less need to pay for support when the economy delivers higher incomes, and because it is costlier to buy the votes of richer individuals. If informational advantages are a central explanation, we would expect increased cellphone coverage to predict improvements in political knowledge and perceptions of government performance.

\subsection{Effects on wealth}

We tested the effect of cellphone coverage expansion on wealth using night-time light density at the (more granular) EA level; we aggregate by taking the EA-level mean value (across pixels) and normalizing by EA population. As shown in Table 3, when estimating Eqns 1-3, there is robust evidence that cellphone coverage expansion predicts greater night-time illumination. In 
our models with full controls, obtaining heavy cellphone coverage predicts a 0.122 S.D. increase in night-time light density (column 3), and a 1 S.D. increase in cellphone coverage predicts a 0.059 S.D. increase in night-time light density. We find broadly similar results using different types of nighttime light aggregation strategies (summing rather than taking the mean, and with or without normalizing by population) (see Table SI-15). We find similar results when analyzing two additional data sources we use to construct wealth indices: Afrobarometer data (Table 4, columns 1-2), ${ }^{4}$ and Census data (Table SI-16).

Table 3: Night-Time Light Density

\begin{tabular}{lcccccccc}
\hline & \multicolumn{3}{c}{ Discretized } & & \multicolumn{3}{c}{ Continuous } \\
\cline { 2 - 3 } \cline { 8 - 9 } & $(1)$ & $(2)$ & $(3)$ & & $(4)$ & $(5)$ & $(6)$ \\
\hline Cellphone Coverage & $0.582^{* * *}$ & $0.333^{* * *}$ & $0.122^{*}$ & & $0.317^{* * *}$ & $0.188^{* * *}$ & $0.059^{*}$ \\
& $(0.064)$ & $(0.067)$ & $(0.067)$ & & $(0.030)$ & $(0.030)$ & $(0.033)$ \\
\hline Observations & 141414 & 141414 & 141414 & & 141414 & 141414 & 141414 \\
$R^{2}$ & 0.93 & 0.94 & 0.97 & & 0.93 & 0.94 & 0.97 \\
Year FE & Yes & No & No & & Yes & No & No \\
Region $\times$ Year FE & No & Yes & Yes & & No & Yes & Yes \\
EA vary slope & No & No & Yes & & No & No & Yes \\
\hline
\end{tabular}

Notes: This table presents estimates for analysis using night-time light density data aggregated at the EA level. The independent variable is dichotomous cellphone coverage measure in models (1)-(3) (which correspond to Eqns 1-3, respectively), and continuous in models (4)-(6) (which correspond to Eqns 1-3, respectively). All models include EA fixed effects. EA vary slope indicates the presence of EA-level time trends. Robust standard errors are shown in parentheses: ${ }^{* * *} p<0.01 ;{ }^{* *} p<0.05 ;{ }^{*} p<0.1$.

\subsection{Effects on perceptions of the economy}

Consistent with a retrospective voting channel, we also find that greater cellphone coverage predicts significantly greater faith in the economy, as captured by this $\mathrm{AB}$ index (Table 4, columns 3-4). In both specifications, a 1 S.D. increase in cellphone access predicts a 0.06 S.D. increase in faith in the economy. This appears to be driven by improvements in perceptions that economic policy benefits the Ghanaian people (Table SI-18, columns 7-8).

\footnotetext{
${ }^{4}$ For analysis of all component variables of the AB wealth index, see Table SI-17.
} 


\subsection{Effects on vote-buying}

Next, we consider how often individuals reported a candidate or someone from a political party offering them food, gifts, or money in return for their vote. Consistent with retrospective voting, in our preferred (full controls) specification, a 1 S.D. increase in cellphone coverage predicts a 0.05 S.D. decrease in vote-buying (Table 4 , column 10).

\subsection{Effects on perceived government performance}

By contrast, we find no evidence that cellphone coverage affected general perceptions of government performance (Table 4, columns 5-6). In Table SI-19, we show that cellphone coverage did not have a statistically significant effect on nearly any of the sub-components of the government performance index.

\subsection{Effects on political knowledge}

There is a single political knowledge question available across multiple rounds of the AB: an indicator for being able to name one's MP. Cellphone coverage does not significantly affect this outcome, as shown in Table 4, columns 7-8. For robustness, we analyze other outcomes crosssectionally, as shown in Table SI-20, finding, again, no evidence of a consistent relationship between cellphone coverage and political knowledge.

\section{Conclusion}

In this letter, we explore the effect of cellphone coverage expansion on electoral outcomes in Ghana during 1996-2016. We show that increases in cellphone coverage confer an incumbency advantage in both presidential and parliamentary elections. We further provide evidence suggesting this incumbency advantage is due to economic improvements boosting wealth and thus retrospective voting.

From a normative perspective our results are somewhat ambiguous. On the one hand, electoral accountability is strengthened when voters respond to improvements in well-being by increasing their support for the incumbent party. To the extent that expansions in cellphone 
coverage reflect the incumbent's success in creating an enabling environment for robust private sector investments and expansions, it is encouraging that citizens reward the incumbent. On the other hand, as elsewhere, our results point to the difficulty voters face in accurately attributing responsibility for shifts in the economy. In this case, citizens may to some extent be rewarding incumbents for decisions (where to invest in new cellphone towers) made by private telecommunications companies.

Since our results can reflect either persuasion of swing voters or a change in evaluative criteria of (past) ethnic voters, future work should further explore the implications of cellphone coverage for a broader set of voting patterns-including how these vary across different types of voters. Future work should also test the generalizability of our findings to other developing countries as well as to additional wealth-conferring communication technologies beyond $2 \mathrm{G}$ cellphone coverage. 


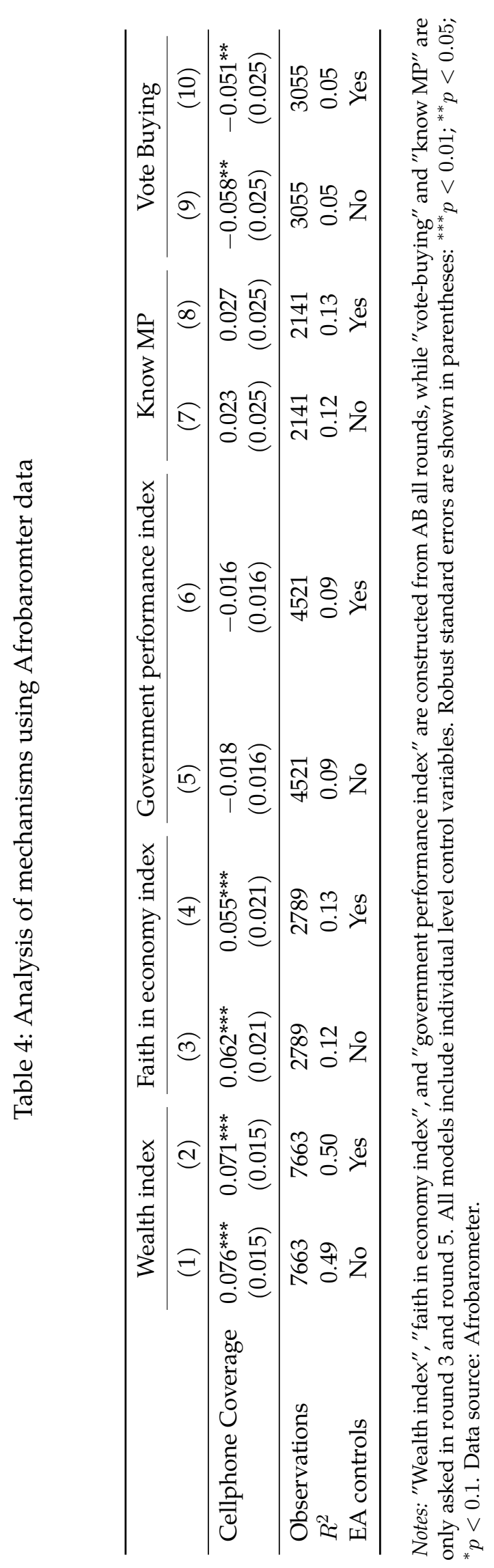




\section{References}

Adida, Claire et al. (2017). "Reducing or reinforcing in-group preferences? An experiment on information and ethnic voting". Quarterly Journal of Political Science 12.4, pp. 437-477.

Aker, Jenny C (2010). "Information from markets near and far: Mobile phones and agricultural markets in Niger". American Economic Journal: Applied Economics 2.3, pp. 46-59.

Aker, Jenny C and Marcel Fafchamps (2015). "Mobile phone coverage and producer markets: Evidence from West Africa". The World Bank Economic Review 29.2, pp. 262-292.

Arias, Eric et al. (2019). "Information provision, voter coordination, and electoral accountability: Evidence from Mexican social networks". American Political Science Review 113.2, pp. 475-498.

Asunka, Joseph et al. (2019). "Electoral fraud or violence: The effect of observers on party manipulation strategies". British Journal of Political Science 49.1, pp. 129-151.

Benedictis-Kessner, Justin de and Christopher Warshaw (2020). "Accountability for the local economy at all levels of government in United States elections". American Political Science Review 114.3, pp. 660-676.

Brierley, Sarah (2021). "Combining patronage and merit in public sector recruitment". The Journal of Politics 83.1, pp. 182-197.

Brierley, Sarah and Eric Kramon (2020). “Party campaign strategies in Ghana: rallies, canvassing and handouts". African Affairs 119.477, pp. 587-603.

Brierley, Sarah and Noah L Nathan (2022). "Motivating the Machine: Which Brokers Do Parties Pay?" Journal of Politics 84.3, pp. 1539-1555.

Burke, Marshall et al. (2021). “Using satellite imagery to understand and promote sustainable development". Science 371.6535, eabe8628.

Callen, Michael et al. (2016). "Improving electoral integrity with information and communications technology". Journal of Experimental Political Science 3.1, pp. 4-17.

Choi, Donghyun Danny, Benjamin Laughlin, and Anna E Schultz (2021). "Mobile Communication Technology and National Identity in Sub-Saharan Africa".

Christensen, Darin and Francisco Garfias (2018). “Can you hear me now? How communication technology affects protest and repression". Quarterly journal of political science 13.1, p. 89.

Cole, Shawn A and A Nilesh Fernando (2021). "'Mobile'izing agricultural advice technology adoption diffusion and sustainability". The Economic Journal 131.633, pp. 192-219.

Donati, Dante (2022). Mobile Internet access and political outcomes: Evidence from South Africa.

Duch, Raymond M. and Randy Stevenson (2006). "Assessing the magnitude of the economic vote over time and across nations". Electoral Studies 25.3, pp. 528-547.

Gonzalez, Robert M (2021). "Cell phone access and election fraud: evidence from a spatial regression discontinuity design in Afghanistan". American Economic Journal: Applied Economics 13.2, pp. 1-51.

Goodman-Bacon, Andrew (2021). "Difference-in-differences with variation in treatment timing". Journal of Econometrics 225.2, pp. 254-277. 
Grossman, Guy, Macartan Humphreys, and Gabriella Sacramone-Lutz (2020). “Information technology and political engagement: Mixed evidence from Uganda". The Journal of Politics 82.4, pp. 1321-1336.

GSMA (2019). "Mobile coverage explorer". CollinsBartholomew. URL https:/ /www. collinsbartholomew. com/mobile-coverage-maps/mobile-coverage-explorer/ (accessed 5.18. 20).

Gupta, Apoorv, Jacopo Ponticelli, and Andrea Tesei (2020). Information, technology adoption and productivity: The role of mobile phones in agriculture. Tech. rep. National Bureau of Economic Research.

Guriev, Sergei, Nikita Melnikov, and Ekaterina Zhuravskaya (2021). “3g internet and confidence in government". The Quarterly Journal of Economics 136.4, pp. 2533-2613.

Harding, Robin (2015). "Attribution and accountability: Voting for roads in Ghana". World Politics 67.4, pp. 656-689.

Healy, Andrew, Katrina Kosec, and Cecilia Hyunjung Mo (2017). "Economic development, mobility, and political discontent: An experimental test of tocqueville's thesis in Pakistan". American Political Science Review 111.3, pp. 605-621.

Hjort, Jonas and Jonas Poulsen (2019). "The arrival of fast internet and employment in Africa". American Economic Review 109.3, pp. 1032-79.

Hoffman, Barak D and James D Long (2013). "Parties, ethnicity, and voting in African elections". Comparative Politics 45.2, pp. 127-146.

Jack, William and Tavneet Suri (2014). "Risk sharing and transactions costs: Evidence from Kenya's mobile money revolution". American Economic Review 104.1, pp. 183-223.

Jensen, Robert (2007). "The digital provide: Information (technology), market performance, and welfare in the South Indian fisheries sector". The quarterly journal of economics 122.3, pp. 879-924.

Klašnja, Marko and Rocío Titiunik (2017). "The incumbency curse: Weak parties, term limits, and unfulfilled accountability". American Political Science Review 111.1, pp. 129-148.

Klaus, Kathleen and Jeffrey W Paller (2017). “Defending the city, defending votes: Campaign strategies in urban Ghana". The Journal of Modern African Studies 55.4, pp. 681-708.

Kosec, Katrina and Leonard Wantchekon (2020). "Can information improve rural governance and service delivery?" World Development 125, p. 104376.

Li, Xuecao et al. (2020). "A harmonized global nighttime light dataset 1992-2018". Scientific data 7.1, pp. 1-9.

Liu, Licheng, Ye Wang, and Yiqing Xu (2021). "A practical guide to counterfactual estimators for causal inference with time-series cross-sectional data". arXiv preprint arXiv:2107.00856.

Manacorda, Marco and Andrea Tesei (2020). "Liberation technology: Mobile phones and political mobilization in Africa". Econometrica 88.2, pp. 533-567.

Mensah, Justice Tei (2021). "Mobile phones and local economic development: a global evidence". Available at SSRN 3811765. 
Mensah, Justice Tei, Kibrom Tafere, and Kibrom A Abay (2022). "Saving Lives through Technology". Policy Research Working Paper 9978.

Nathan, Noah L (2019). Electoral politics and Africa's Urban transition: class and ethnicity in Ghana. Cambridge University Press.

Pierskalla, Jan H and Florian M Hollenbach (2013). "Technology and collective action: The effect of cell phone coverage on political violence in Africa". American Political Science Review 107.2, pp. 207-224.

Sances, Michael W (2017). "Attribution errors in federalist systems: When voters punish the president for local tax increases". The Journal of Politics 79.4, pp. 1286-1301.

Shapiro, Jacob N and David A Siegel (2015). "Coordination and security: How mobile communications affect insurgency". Journal of Peace Research 52.3, pp. 312-322.

Shockley, Bethany and Justin J Gengler (2020). "Social identity and coethnic voting in the Middle East: Experimental evidence from Qatar". Electoral Studies 67, p. 102213.

Warren, T Camber (2015). “Explosive connections? Mass media, social media, and the geography of collective violence in African states". Journal of Peace Research 52.3, pp. 297-311.

Weidmann, Nils B (2016). "A closer look at reporting bias in conflict event data". American Journal of Political Science 60.1, pp. 206-218.

World Bank (2022). World Development Indicators. 


\section{SUPPLEMENTARY INFORMATION}

\section{A. Main Analysis Data Construction}

The unit of analysis in our primary political outcomes analysis is the electoral constituency. We construct a panel dataset of constituency-level electoral data, cellphone coverage, and census data (e.g., demographics and measures of wealth) for the six elections between 1996 and 2016 as described below.

Electoral Data (key outcome variables) The dependent variables are electoral outcomes from the 1996, 2000, 2004, 2008, 2012, and 2016 presidential and parliamentary elections provided by the Electoral Commission of Ghana at the constituency level. The number of constituencies was increased twice during the period of our study. There were 200 constituencies during the 1996 and 2000 elections. This was increased to 230 constituencies for the 2004 and 2008 elections. This was increased again to 275 constituencies for the 2012 and 2016 elections. These new constituencies were primarily the result of splitting existing constituencies in two. To construct a panel with stable constituency units across elections, we aggregate the electoral results of constituencies that were split into the earliest constituency units, the 200 1996/2000 constituencies. We also join split constituencies in the 2016 constituency shapefile to create the 1996/2000 shapefile that we use to calculate cellphone coverage. Several cases of new districts that were not simple splits of existing districts or ambiguous constituency names in the electoral data required dropping a several constituencies. The resulting dataset has between 188 and 196 constituencies for each election. We merge the constituency-level electoral data with EA-level cellphone coverage and census data, first spatially merging the EA-level geometries with a constituency shapefile that gives us unique constituency identifiers.

GSMA Data (key independent variable) Our key input variable was constructed using coverage maps purchased from the GSM Association (GSMA), a cellphone network provider industry group, which collects and report global cellphone coverage data in partnership with Collins Bartholomew, a digital mapping provider. This dataset has been used in past research, including Buys et al. (2009), Pierskalla and Hollenbach (2013), Christensen and Garfias (2018), and Manacorda and Tesei (2020). The Collins Bartholomew data comes from submissions made by cellphone operators in each country to construct roaming coverage and is reported in the form of (approximately) yearly global coverage shapefiles outlining the extent of 2G, 3G, and $4 \mathrm{G}$ coverage (GSMA, 2019). We convert these polygons into rasters, ${ }^{5}$ for easier subsequent processing. We then aggregate the EA-level cellphone coverage measure to the constituency

\footnotetext{
${ }^{5}$ Since the coverage polygons are binary, the rasterization simply converts these coverage extents into matrices of binary coverage indicators at the cell ( 0.05 decimal degrees, or $5 \mathrm{~km}$ at the equator) level. Rasterisation was performed using https://corteva.github.io/geocube/stable/index.html.
} 
level by taking a population-weighted average of EA-level coverage measures. Figure 1 shows cellphone coverage expansion in Ghana between 2000 and 20016 at the constituency level.

Ghanaian Census We obtained Enumeration-Area (EA) level data for the 2000 and 2010 census and EA-level shapefiles from the Ghanaian Statistical Service (GSS). We merge the two censuses with their corresponding geometries to construct an EA-level panel dataset. We then spatially merge the EA-level census dataset with yearly cellphone coverage rasters to construct coverage measures for each year between 2000 and 2008. We compute zonal-statistics, which average the value of a raster in each polygon. In this case, since the raster values are binary, this gives us the share of each EA that has cellphone coverage in each year. Computations were performed using rasterstats, a Python module for summarizing geospatial raster datasets.

Wealth measures Household wealth is a key outcome in this study's causal chain. The 2000 and 2010 EA-level census datasets contain the following eleven variables that proxy wealth: share of households with a roof made of materials better than earth, mud, bamboo, or leaf; share of households with walls made of materials better than earth or mud; share of households with a floor made of materials better than earth or mud; share of households with electricity; share of households using sewerage system; share of household with piped-water; share of households with collected rubbish; share of households with toilets; share of households with improved water source; share of the population that is not forced to work for profit; and literacy rate. We standardized these proxy variables across the 2000 and 2010 censuses so that they are at the same scale and of the same direction (larger value indicates greater wealth). These variables are positively correlated with each other and have high consistency based on Cronbach's alpha (larger than 0.8). We constructed a wealth score by taking a simple average across these wealthrelated variables. It was further standardized to mean 0 and standard deviation 1.

Table SI-1: Descriptive statistics, main analysis

\begin{tabular}{lcccccc}
\hline \multicolumn{7}{c}{ Panel A: Dependent variables } \\
\hline Presidential Election Vote Share & Mean & Median & St. Dev. & Min & Max & N \\
\hline Incumbent Vote Share (1996) & 0.585 & 0.572 & 0.2 & 0.182 & 0.982 & 188 \\
Incumbent Vote Share (2000) & 0.445 & 0.488 & 0.235 & 0.01 & 0.882 & 193 \\
Incumbent Vote Share (2004) & 0.499 & 0.528 & 0.206 & 0.037 & 0.895 & 192 \\
Incumbent Vote Share (2008) & 0.492 & 0.486 & 0.182 & 0.114 & 0.96 & 193 \\
Incumbent Vote Share (2012) & 0.531 & 0.533 & 0.182 & 0.139 & 0.959 & 193 \\
Incumbent Vote Share (2016) & 0.505 & 0.509 & 0.193 & 0.054 & 0.893 & 192 \\
\hline Parliamentary Election: Vote Share & & & & & & \\
Incumbent Vote Share (1996) & 0.61 & 0.592 & 0.135 & 0.215 & 0.958 & 187 \\
Incumbent Vote Share (2000) & 0.584 & 0.562 & 0.125 & 0.258 & 0.909 & 196 \\
Incumbent Vote Share (2004) & 0.59 & 0.569 & 0.119 & 0.265 & 0.878 & 196 \\
Incumbent Vote Share (2008) & 0.575 & 0.553 & 0.121 & 0.287 & 0.919 & 196 \\
Incumbent Vote Share (2012) & 0.584 & 0.552 & 0.11 & 0.309 & 0.924 & 196
\end{tabular}




\begin{tabular}{|c|c|c|c|c|c|c|}
\hline Incumbent Vote Share (2016) & 0.598 & 0.572 & 0.113 & 0.342 & 0.91 & 195 \\
\hline \multicolumn{7}{|l|}{ Election Turnout (Prez \& Parl Average) } \\
\hline Turnout (1996) & 0.785 & 0.792 & 0.059 & 0.515 & 0.935 & 188 \\
\hline Turnout (2000) & 0.628 & 0.628 & 0.068 & 0.411 & 0.981 & 193 \\
\hline Turnout (2004) & 0.844 & 0.851 & 0.069 & 0.439 & 1.116 & 192 \\
\hline Turnout (2008) & 0.693 & 0.692 & 0.049 & 0.532 & 0.801 & 193 \\
\hline Turnout (2012) & 0.793 & 0.785 & 0.058 & 0.651 & 1.062 & 193 \\
\hline Turnout (2016) & 0.694 & 0.693 & 0.062 & 0.529 & 0.926 & 192 \\
\hline \multicolumn{7}{|l|}{ Independent Variable } \\
\hline Cellphone Coverage (2000) & 0.191 & 0 & 0.347 & 0 & 1 & 196 \\
\hline Cellphone Coverage (2004) & 0.516 & 0.552 & 0.377 & 0 & 1 & 196 \\
\hline Cellphone Coverage (2008) & 0.809 & 0.952 & 0.264 & 0 & 1 & 196 \\
\hline Cellphone Coverage (2012) & 0.826 & 0.954 & 0.254 & 0 & 1 & 196 \\
\hline Cellphone Coverage (2016) & 0.969 & 0.988 & 0.048 & 0.731 & 1 & 195 \\
\hline \multicolumn{7}{|c|}{ Panel B: Other variables } \\
\hline \multicolumn{7}{|l|}{ Constituency Level } \\
\hline Wealth Index (2000) & 39.324 & 38.681 & 15.607 & 11.995 & 75.473 & 216 \\
\hline Wealth Index (2010) & 45.753 & 45.153 & 13.598 & 16.024 & 74.587 & 216 \\
\hline \% Ethnic-NPP (2000) & 0.385 & 0.332 & 0.308 & 0.011 & 0.911 & 216 \\
\hline \% Ethnic-NDC (2000) & 0.507 & 0.502 & 0.294 & 0.058 & 0.966 & 216 \\
\hline Population (2000) & 85433.26 & 78249.5 & 44818.66 & 1987 & 301783 & 196 \\
\hline Population Density $(\times 1000)(2000)$ & 1210.498 & 103.402 & 3664.19 & 1.484 & 26068.158 & 196 \\
\hline \multicolumn{7}{|l|}{ Enumeration Area Level } \\
\hline Wealth Index (2000) & 46.251 & 46.586 & 20.352 & 1.998 & 94.709 & 22421 \\
\hline Wealth Index (2010) & 50.753 & 52.578 & 17.596 & 0.417 & 98.213 & 22421 \\
\hline Nightlight Density Mean (1996) & 2.923 & 0 & 9.545 & 0 & 63 & 23964 \\
\hline Nightlight Density Mean (2000) & 3.005 & 0 & 9.545 & 0 & 62 & 23964 \\
\hline Nightlight Density Mean (2004) & 3.288 & 0 & 9.725 & 0 & 59 & 23964 \\
\hline Nightlight Density Mean (2008) & 3.263 & 0 & 9.798 & 0 & 60 & 23964 \\
\hline Nightlight Density Mean (2012) & 4.116 & 0 & 11.442 & 0 & 63 & 23964 \\
\hline Nightlight Density Mean (2016) & 6.934 & 5.551 & 12.027 & 0 & 62 & 23964 \\
\hline Nightlight Density Sum (1996) & 3.497 & 0 & 10.503 & 0 & 63 & 23964 \\
\hline Nightlight Density Sum (2000) & 3.626 & 0 & 10.398 & 0 & 62 & 23964 \\
\hline Nightlight Density Sum (2004) & 3.888 & 0 & 10.392 & 0 & 59 & 23964 \\
\hline Nightlight Density Sum (2008) & 3.829 & 0 & 10.393 & 0 & 60 & 23964 \\
\hline Nightlight Density Sum (2012) & 4.907 & 0 & 12.278 & 0 & 63 & 23964 \\
\hline Nightlight Density Sum (2016) & 7.713 & 6 & 12.697 & 0 & 62 & 23964 \\
\hline \% Ethnic-NPP (2000) & 0.398 & 0.308 & 0.349 & 0 & 1 & 22421 \\
\hline \% Ethnic-NDC (2000) & 0.504 & 0.519 & 0.344 & 0 & 1 & 22421 \\
\hline
\end{tabular}

Notes: This table presents descriptive statistics for variables used in our main analysis. For both presidential and parliamentary elections, the vote share is the vote share of the incumbent party. 


\section{B. Afrobarometer Data Construction}

We studied mechanisms and performed robustness tests by using publicly available, nationally representative Afrobarometer $(\mathrm{AB})$ survey data. We scrutinized survey questions in each round thoroughly and selected pertinent questions that mainly target the following five key outcome categories: wealth (as a robustness check on the census wealth index described above), faith in economy, evaluation of government performance, political knowledge, and reported vote buying. For each of these outcome categories, we constructed an index utilizing all of the component variables capturing that outcome category.

Starting with the geo-labeled Afrobarometer $(\mathrm{AB})$ data, we located most of the respondents in Enumeration Areas and the rest, 2000 constituencies. We further assigned each respondents EA-level covariates values. We used all data available from round 1 (1999) to round 6 (2015). We excluded the last two rounds because the year in which they were conducted post-dated the last election in our study. When common questions included in different rounds have different response categories, we re-coded responses (e.g., by collapsing categories where applicable) so that they are consistently and comparably coded across rounds. We also re-coded responses such that larger values always represent better outcomes (e.g., more wealth, greater faith in the economy, more positive perceptions of government performance, or greater political knowledge). Note that not all variables are included in every AB round. We utilized as many rounds as possible for each outcome. Indexes are by construction missing for a round if any of its component variables is missing for that round. Details on each component variable in each category, along with their original question wording and response re-coding scheme, are detailed in Table SI-3.

Individual-level controls include both demographic and geospatial variables. Age is a continuous variable. Education is re-coded as an indicator for the respondent having completed secondary education or higher. Religion is re-coded into three dummies: Christian, Muslim, or other. Gender is an indicator for male respondents. Moreover, using respondents' coordinates, we calculated distance to Ghana's border, Accra, closest constituency centroid, the shortest distance to major roads, and shortest distance to any road for each respondent.

EA-level controls are generated from 2000 census data, including wealth index, share of population that would most likely support NPP or NDC based on ethnicity. Note that for less than $5 \%$ respondents, we could not locate their EA because available geo-coded administration boundary datasets lack information for some EAs. For those repondents, we impute values of control variables using constituency-level values.

Wealth index is constructed as the simple average of five questions that ask respondents how often they've gone without food, water, medicine, cooking fuel, or cash income. These variables take on a value from 0 (always gone without food, etc.) to 4 (never gone without food, etc.). 
Faith in economy index is calculated by averaging across 5 variables that reflect respondents' opinions regarding current national economic conditions. These variables are nominal where 1 represents the most negative attitude (e.g. the present economic condition in Ghana is very bad; the government's economic policy hurts people more than benefits them.) and the largest value ( 4 or 5$)$ the most positive.

Government performance index is comprised of a series of questions about respondents' perceptions of how well the government is dealing with the following issues: the economy, health services, education, water access, food supply, job opportunities, price stability, inequality, crime, corruption, and HIV-AIDS. Responses range from 1 (very badly) to 4 (very well).

Political knowledge includes several dummy variables that ask if the respondent can name their MP, Minister of Finance, deputy president, local government councillor, presidential term limits, party with the most parliamentary seats, and the person who is responsible for a law being constitutional.

Vote buying is a question asked only in rounds 3 and 5 about whether the respondent got paid or offered anything in return for their vote.

Descriptive statistics All Afrobarometer variables that appear in our empirical analysis are summarized in Table SI-2.

Table SI-2: Descriptive statistics, individual-level Afrobarometer (AB) analysis

\begin{tabular}{lccccccc}
\hline Treatment Variable & Mean & Median & St. Dev. & Min & Max & N & Round \\
\hline Cellphone Coverage & 0.741 & 1 & 0.421 & 0 & 1 & 9061 & Round 1-6 \\
\hline Dependent Variables & & & & & & & \\
\hline Welfare & & & & & & & \\
\hline Wealth Index & 2.149 & 2.133 & 0.626 & 0 & 6 & 9061 & Round 1-6 \\
Enough food & 3.411 & 4 & 1.029 & 0 & 4 & 9041 & Round 1-6 \\
Enough water & 3.283 & 4 & 1.197 & 0 & 4 & 9048 & Round 1-6 \\
Enough medicine & 3.292 & 4 & 1.137 & 0 & 4 & 9019 & Round 1-6 \\
Enough cooking fuel & 3.57 & 4 & 0.912 & 0 & 4 & 7750 & Round 2-6 \\
Enough cash income & 2.581 & 3 & 1.378 & 0 & 4 & 7725 & Round 2-6 \\
Faith in economy & & & & & & & \\
\hline Faith in Economy index & 2.542 & 2.5 & 0.784 & 1 & 5 & 5514 & Round 2-5 \\
Current economy condition & 2.467 & 2 & 1.354 & 1 & 5 & 5443 & Round 2-5 \\
Past economy condition & 2.979 & 3 & 1.086 & 1 & 5 & 5426 & Round 2-5 \\
Economy policy benefits people & 2.515 & 2 & 1.544 & 1 & 5 & 3033 & Round 2-4 \\
More jobs created & 2.079 & 2 & 0.972 & 1 & 4 & 8757 & Round 2-6 \\
Economy improved & 2.334 & 2 & 1.025 & 1 & 4 & 7521 & Round 2-6 \\
\hline
\end{tabular}




\begin{tabular}{|c|c|c|c|c|c|c|c|}
\hline \multicolumn{8}{|l|}{ Government Performance } \\
\hline Government performance index & 2.323 & 2.375 & 0.765 & 1 & 4 & 8974 & Round 1-6 \\
\hline Economy improved & 2.334 & 2 & 1.025 & 1 & 4 & 7521 & Round 2-6 \\
\hline More jobs created & 2.079 & 2 & 0.972 & 1 & 4 & 8757 & Round 1-6 \\
\hline Price stabilized & 1.962 & 2 & 0.976 & 1 & 4 & 8862 & Round 1-6 \\
\hline Inequality reduced & 1.94 & 2 & 0.939 & 1 & 4 & 8575 & Round 1-6 \\
\hline Crime reduced & 2.558 & 3 & 1.049 & 1 & 4 & 8808 & Round 1-6 \\
\hline Better Health Services & 2.57 & 3 & 1.008 & 1 & 4 & 8861 & \\
\hline Better education & 2.526 & 3 & 1.013 & 1 & 4 & 8865 & Round 1-6 \\
\hline Better water condition & 2.352 & 2 & 1.002 & 1 & 4 & 7592 & Round 2-6 \\
\hline Better food provision & 2.237 & 2 & 0.979 & 1 & 4 & 7460 & Round 2-6 \\
\hline Less corruption & 2.238 & 2 & 1.055 & 1 & 4 & 8482 & Round 1-6 \\
\hline HIV / AIDS issue improved & 3.11 & 3 & 0.906 & 1 & 4 & 5110 & Round 2-5 \\
\hline \multicolumn{8}{|l|}{ Political Knowledge } \\
\hline $\mathrm{MP}$ & 0.582 & 1 & 0.493 & 0 & 1 & 2141 & Round 3,4 \\
\hline Minister of Finance & 0.216 & 0 & 0.412 & 0 & 1 & 1083 & Round 4 \\
\hline Local gov. councilor & 0.307 & 0 & 0.462 & 0 & 1 & 1058 & Round 3 \\
\hline Deputy president & 0.704 & 1 & 0.457 & 0 & 1 & 1058 & Round 3 \\
\hline Party with the most seats & 0.733 & 1 & 0.442 & 0 & 1 & 1058 & Round 3 \\
\hline Term limits knowledge & 0.693 & 1 & 0.462 & 0 & 1 & 1058 & Round 3 \\
\hline Const. law knowledge & 0.144 & 0 & 0.351 & 0 & 1 & 1058 & Round 3 \\
\hline Vote buying & 0.164 & 0 & 0.587 & 0 & 3 & 3055 & Round 3,5 \\
\hline \multicolumn{8}{|l|}{ Individual-level controls } \\
\hline$\overline{\text { Age }}$ & 40 & 35 & 43 & 18 & 99 & 9061 & \\
\hline Male indicator & 0.497 & 0 & 0.5 & 0 & 1 & 9061 & \\
\hline Secondary or Higher education & 0.485 & 0 & 0.5 & 0 & 1 & 9061 & \\
\hline Christian & 0.636 & 1 & 0.481 & 0 & 1 & 9061 & \\
\hline Muslim & 0.123 & 0 & 0.328 & 0 & 1 & 9061 & \\
\hline Distance to border $(\mathrm{km})$ & 57.815 & 36.059 & 56.161 & 0.008 & 185.754 & 9061 & \\
\hline Distance to Accra (km) & 202.794 & 184.723 & 162.961 & 1.303 & 648.536 & 9061 & \\
\hline Distance to constituency centroid (km) & 7.647 & 6.468 & 6.457 & 0.089 & 43.919 & 9061 & \\
\hline Distance to main road $(\mathrm{km})$ & 18.941 & 6.584 & 27.046 & 0.002 & 148.703 & 9061 & \\
\hline Distance to any road $(\mathrm{km})$ & 1.116 & 0.448 & 1.712 & 0 & 18.048 & 9061 & \\
\hline
\end{tabular}

Notes: This table presents descriptive statistics for variables used in our AB analysis. 


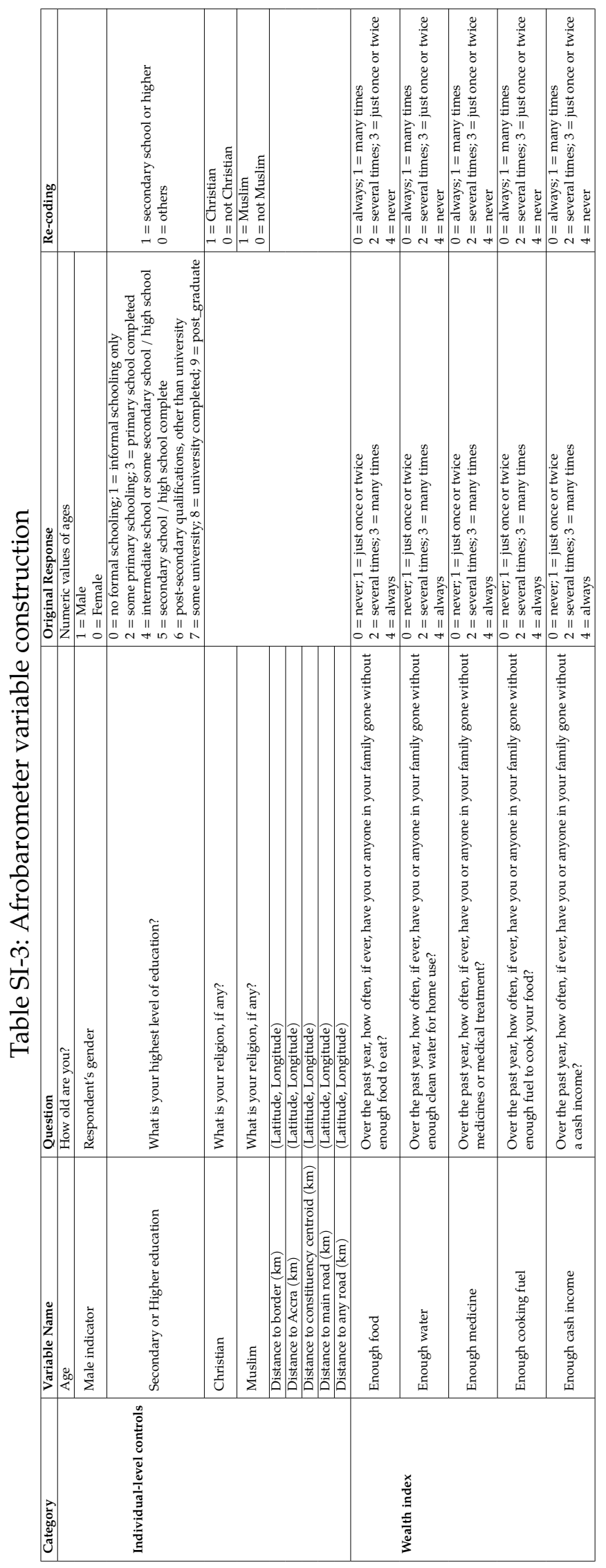




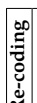

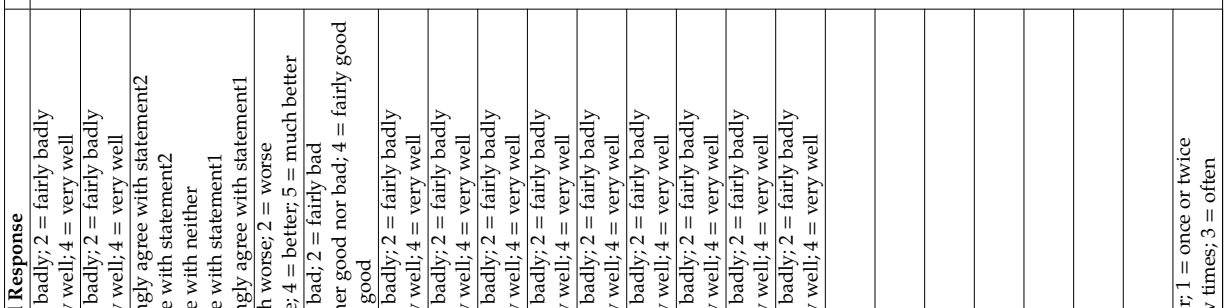

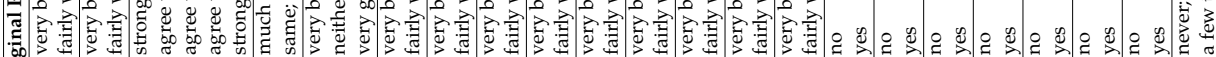

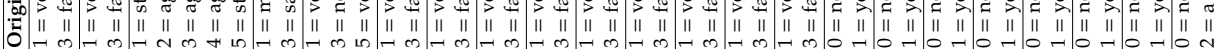

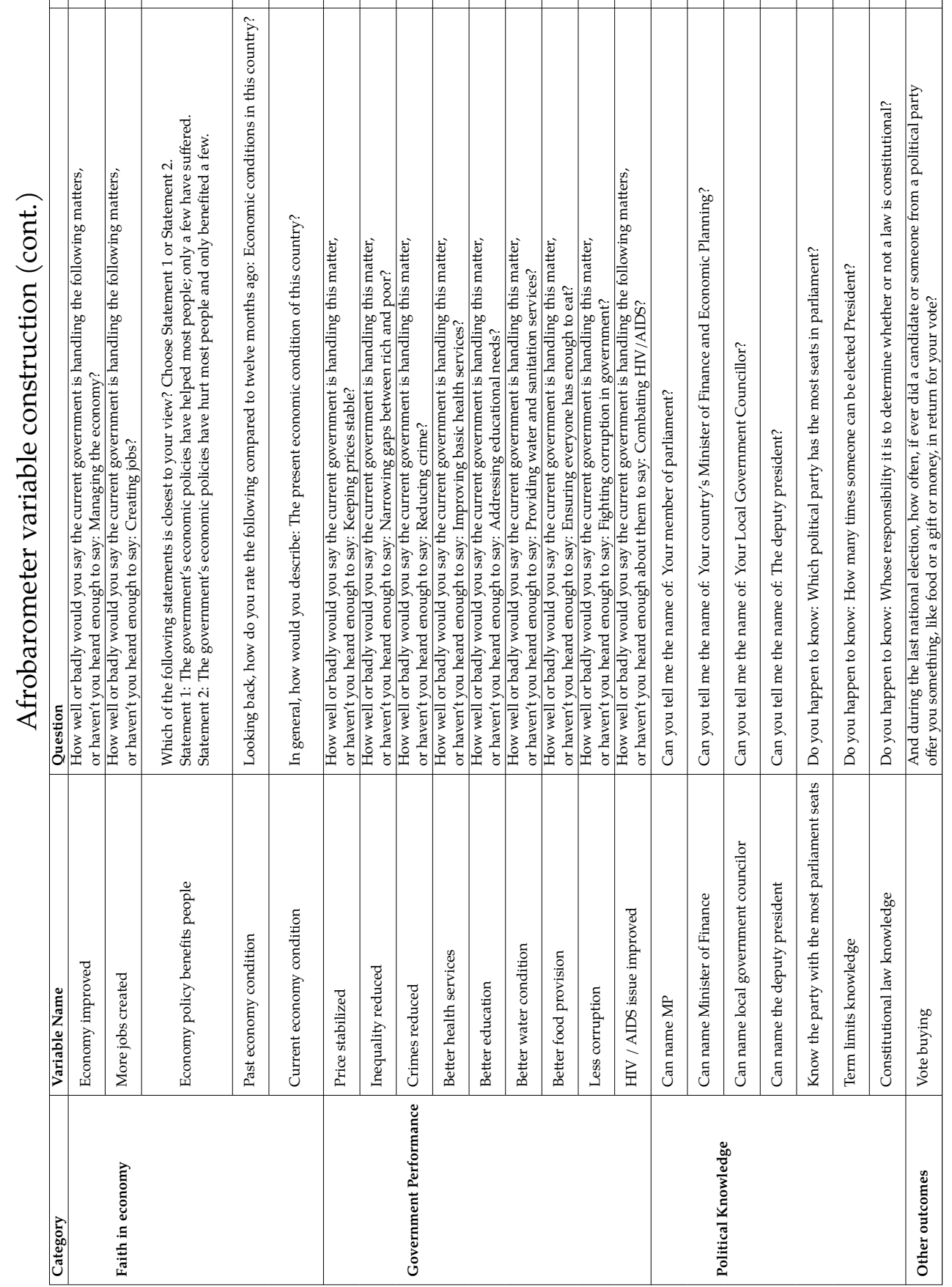




\section{Validation of Cellphone Coverage Measure}

An essential assumption for all mechanisms linking cellphone coverage and political outcomes is that cellphone coverage leads to increased ownership and usage of cellphones. To verify the effect of cellphone coverage on cellphone ownership we use Demographic and Health Surveys (DHS), which include the question, "Does your household have a mobile telephone?" across multiple survey rounds. We include all four rounds in which DHS included this question and collected latitude and longitude coordinates. These surveys were conducted in 2008, 2014, 2016, and 2017. We measure cellphone coverage for DHS respondents with the GSMA data using the procedure described in SI Section A.

Models follow the same cross-sectional specifications we use for analysis of Afrobarometer data, shown in equation 4 . We include pretreatment household-level covariates: age and gender of the household head. As with the regressions using Afrobarometer data, we also include pretreatment covariates derived from 2000 Ghanaian census: EA-level wealth score and the share of population likely to support the NPP and likely to support the NDC. Results shown in Table SI-4 reveal that cellphone coverage increases household cellphone ownership by 17 percentage points when moving from zero to full cellphone coverage.

We evaluate the increase in cellphone use due to cellphone coverage using Afrobarometer rounds 4 and 5, surveyed in 2009 and 2012. These are the only Afrobarometer surveys that include questions that allow us to measure changes in cellphone use over time during the timeframe of the GSMA coverage data. In the round 4 survey Afrobarometer asked, "How often do you use: A mobile phone?" and coded responses of never, less than once a month, a few times a month, a few times a week, or every day. In round 5, Afrobarometer split the question on cellphone use into three questions: "How often do you normally use a mobile phone to: Make or receive a call?", "How often do you normally use a mobile phone to: Send or receive a text message or SMS?", and "How often do you normally use a mobile phone to: Send or receive money or pay a bill?" In round 5, the responses were coded never, less than one time per day, one or two times per day, three or four times per, or five or more times per day.

From these questions we construct two variables, measuring both the extensive and intensive margins of cellphone use. The first is a variable indicating the respondent used a cellphone at all, for any purpose. The second is a variable indicating the respondent used a cellphone at least daily, coded as 1 if the respondent answered that they used a cellphone for any of these purposes once or more a day and 0 if the respond reported using a cellphone less than once a day or never. Specifications follow equation 4 and include pretreatment household-level covariates pretreatment covariates derived from 2000 Ghanaian census as described in SI section B. Results shown in Table SI-5 show that cellphone coverage both increases the likelihood individuals ever use a cellphone and the likelihood they use a cellphone daily. 
Table SI-4: DHS: Cellphone ownership

\begin{tabular}{lcccc}
\hline & \multicolumn{2}{c}{ Standardized variables } & \multicolumn{2}{c}{ Unstandardized variables } \\
\cline { 2 - 5 } & $(1)$ & $(2)$ & $(3)$ & $(4)$ \\
\hline Cellphone Coverage & $0.038^{* * *}$ & $0.038^{* * *}$ & $0.178^{* * *}$ & $0.176^{* * *}$ \\
& $(0.002)$ & $(0.002)$ & $(0.010)$ & $(0.010)$ \\
\hline Observations & 52379 & 52379 & 52379 & 52379 \\
$R^{2}$ & 0.206 & 0.208 & 0.206 & 0.208 \\
Const. controls & No & Yes & No & Yes \\
\hline
\end{tabular}

Notes: This table presents coefficient estimates for household cellphone ownership using DHS data. All models are cross-sectional specifications as shown in Eqn 4. All models include pretreatment household-level controls, the age and gender of the household head. In models (1)-(3) variables for cellphone coverage, wealth, and the percentage of the population that are members of ethnic groups that tend of vote for the NPP and NDC have been standardized to a mean of 0 and a standard deviation of 1 . In models (4)-(6) these variables have not been standardized. Const. stands for constituency. All models include household level control variables.

Robust standard errors are shown in parentheses: ${ }^{* * *} p<0.01{ }^{* *} p<0.05$; $^{*} p<0.1$.

Data source: DHS.

Table SI-5: Afrobarometer: Cellphone use

\begin{tabular}{lcccc}
\hline & \multicolumn{2}{c}{ Ever use cellphone } & \multicolumn{2}{c}{ Use cellphone daily } \\
\cline { 2 - 5 } & $(1)$ & $(2)$ & $(3)$ & $(4)$ \\
\hline Cellphone Coverage & $0.026^{* * *}$ & $0.025^{* * *}$ & $0.015^{* *}$ & $0.014^{*}$ \\
& $(0.007)$ & $(0.007)$ & $(0.008)$ & $(0.008)$ \\
\hline Observations & 3320 & 3320 & 3320 & 3320 \\
$R^{2}$ & 0.210 & 0.213 & 0.213 & 0.255 \\
Const. controls & No & Yes & No & Yes \\
\hline
\end{tabular}

Notes: This table presents coefficient estimates for daily cellphone use using data from Afrobarometer rounds 4 and 5. All models are cross-sectional specifications as shown in eqn 4. Models (1)-(3) have an an outcome indicating whether the respondent ever reports using a cellphone. The outcome of models (4)-(6) is whether the respondent reports using a cellphone daily. All models include pretreatment individual-level controls. Const. stands for constituency. All models include individual level control variables.

Robust standard errors are shown in parentheses: ${ }^{* * *} p<0.01 ;{ }^{* *} p<0.05 ;{ }^{*} p<0.1$.

Data source: Afrobarometer.

\section{Model Assumptions of Election Outcome Analysis}

In this section we test key assumptions of our difference-in-differences models (equations 13), which estimate the effect of cellphone coverage expansion on incumbents' electoral performance. First, we rule out reverse causality by showing that while mobile coverage predicts future electoral performance; incumbent vote share does not predict where mobile coverage expansions take place. Second, we demonstrate the validity of the assumption of the linearity of potential outcomes, which is necessary given that our treatment variable (cellphone coverage) is continuous. Third, we show that the effects of cellphone coverage expansion in time $t$ are limited to elections in that same year, and do not carry over to future elections. Third, 


\section{D.1. Reverse causality}

In Table SI-6, we examine whether cellphone coverage expansions were strategically rolled out to regions favoring the incumbent, which would invalidate the causal conclusions we draw from the panel regressions in the main paper. To test this, we regress present cellphone coverage expansion on past incumbent vote share. Large positive coefficients for incumbent vote share in these regressions would suggest that coverage expansions were targeted to constituencies that already favored the incumbent and invalidate our conclusions. They would suggest that political considerations - as opposed to merely private sector profit maximization motivated these expansions of cellphone coverage. Results from our preferred specification (columns 4 and 8 ) suggest that targeting was statistically indistinguishable from 0 , which gives us confidence in the validity of our study's design.

Table SI-6: Regressions of present coverage expansions on past electoral outcomes

\begin{tabular}{lcccccccc}
\hline & $(1)$ & $(2)$ & $(3)$ & $(4)$ & $(5)$ & $(6)$ & $(7)$ & $(8)$ \\
\hline Vote Share Presidential & 0.017 & 0.028 & 0.021 & 0.006 & & & & \\
& $(0.015)$ & $(0.018)$ & $(0.028)$ & $(0.036)$ & & & & \\
Vote Share Parlimentary & & & & & 0.022 & -0.033 & 0.004 & 0.028 \\
& & & & & $(0.021)$ & $(0.037)$ & $(0.036)$ & $(0.044)$ \\
Population & 0.004 & & & & 0.005 & & & \\
& $(0.023)$ & & & & $(0.023)$ & & & \\
Population Density & $-0.031^{*}$ & & & & $-0.029^{*}$ & & & \\
& $(0.017)$ & & & & $(0.017)$ & & & \\
Wealth Index & $0.436^{* * *}$ & & & & $0.433^{* * *}$ & & & \\
& $(0.028)$ & & & & $(0.028)$ & & 939 \\
\hline Observations & 940 & 940 & 940 & 940 & 939 & 939 & 939 & \\
$R^{2}$ & 0.67 & 0.77 & 0.84 & 0.89 & 0.67 & 0.77 & 0.84 & 0.89 \\
Const. FE & No & Yes & Yes & Yes & No & Yes & Yes & Yes \\
Year FE & Yes & Yes & No & No & Yes & Yes & No & No \\
Region $\times$ Year FE & No & No & Yes & Yes & No & No & Yes & Yes \\
Const. vary slope & No & No & No & Yes & No & No & No & Yes \\
\hline
\end{tabular}

Notes: This table presents results of reverse causality analysis. In all models, the dependent variable is the continuous cellphone coverage measure standardized to be with mean 0 and standard deviation 1 . Models (1)-(4) use presidential election data and models (5)-(8) analyze parliamentary election. Control variables population, population density, and wealth index are generated from 2000 census data. Model (2) and model (6) correspond model specification expressed in equation 1. Model (3) and model (7) use equation 2, model (4) and (8) correspond to equation 3. Const. stands for constituency.

Robust standard errors are shown in parentheses: ${ }^{* * *} p<0.01{ }^{* *} p<0.05{ }^{*} p<0.1$.

Data source: Electoral commission of Ghana.

\section{D.2. Non-parametric Regression Estimates}

Since we are interested in the effect of a continuous treatment (change in cellphone coverage) on election outcomes, we rely on the implicit assumption of the linearity of potential outcomes $Y(w)$ for treatment $w \in \mathbb{R}$, with the quantity of interest being its first derivative, $Y^{\prime}(w)$ (change in potential outcomes for small changes in treatment from $w$ to $w^{\prime}$, the limiting case of which de- 
fines the first derivative). For the linear regression coefficient to accurately capture this quantity of interest, the regression line must be approximately linear; otherwise, a more flexible estimator is required.

Figure SI-1: Non-parametric regression

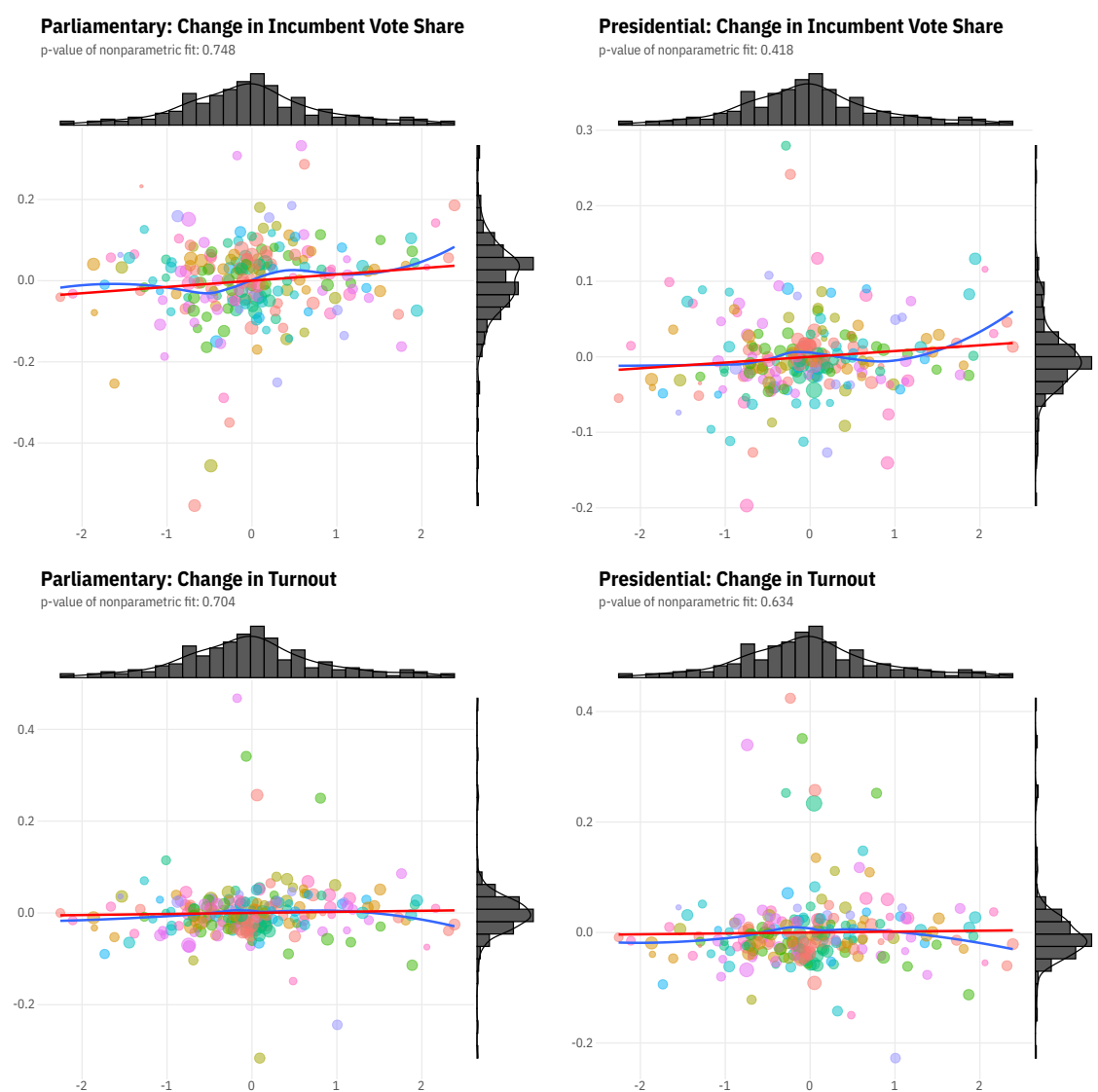

Notes: Non-parametric regression results for parliamentary political outcomes regressed on coverage expansion. The p-value tests the superiority of the non-parametric model against the linear function. We fail to reject the null that the parametric linear regression and non-parametric regression fit equally well, based on the test proposed by Cattaneo et al. (2021) (implemented in binsreg)

Evaluating the suitability of the linear functional form is challenging in the panel data setting, since we're identifying treatment effects from over-time variation in the treatment and outcome. To make progress, we restrict our attention to the two periods where the largest coverage expansions occurred (2004 - 2008), and plot changes in electoral outcomes as a function of changes in coverage. We plot non-parametric regression curves of (residualized) political outcomes on (residualized) coverage expansion, as shown in Figure SI-1 in blue, and compare this to the linear fit in red. On cursory examination, these curves look very similar. We then formally test the null that the linear fit is comparable to the non-parametric fit using the test proposed in Cattaneo et al. (2021). We fail to reject the null that the linear fit is as good as the non-parametric fit for all four outcomes. This justifies linear regression in the primary analysis. 


\section{D.3. Carry over examinations}

Next, we analyze whether electoral outcomes in year $t$ that we attribute to cellphone coverage expansion in that year are in fact due to previous expansions in cellphone coverage. If this were the case, it would invalidate the "no carry-over" assumption required of our model. In Table SI-7, we examine whether the effects of cellphone coverage expansion in time $t$ are contemporaneous for presidential elections. Models (1) - (3), corresponding to Eqns 1-3, respectively, regress incumbent vote share (Panel A) or turnout (Panel B) on continuous cellphone coverage in the previous election year. We find little evidence of carry-over, with small point estimates and broadly null effects. Similarly null results hold when considering parliamentary elections (Table SI-8.) We conclude that the "no carry-over" assumption is valid across Eqns 1-3.

Table SI-7: Presidential Election Carry-over Analysis

\begin{tabular}{|c|c|c|c|c|c|c|}
\hline \multicolumn{7}{|c|}{ Panel A: Incumbent Vote Share in Presidential election } \\
\hline & \multicolumn{3}{|c|}{ Lagged IV } & \multicolumn{3}{|c|}{ Lagged DV } \\
\hline & $(1)$ & $(2)$ & (3) & $(4)$ & (5) & $(6)$ \\
\hline Cellphone Coverage & $\begin{array}{c}0.000 \\
(0.014)\end{array}$ & $\begin{array}{c}0.003 \\
(0.010)\end{array}$ & $\begin{array}{c}0.008 \\
(0.015)\end{array}$ & $\begin{array}{l}-0.008 \\
(0.027)\end{array}$ & $\begin{array}{l}-0.006 \\
(0.024)\end{array}$ & $\begin{array}{c}0.003 \\
(0.044)\end{array}$ \\
\hline $\begin{array}{l}\text { Observations } \\
R^{2}\end{array}$ & $\begin{array}{l}960 \\
0.64\end{array}$ & $\begin{array}{l}960 \\
0.83\end{array}$ & $\begin{array}{l}960 \\
0.85\end{array}$ & $\begin{array}{l}767 \\
0.63\end{array}$ & $\begin{array}{l}767 \\
0.82\end{array}$ & $\begin{array}{l}767 \\
0.83\end{array}$ \\
\hline \multicolumn{7}{|c|}{ Panel B: Turnout in Presidential election } \\
\hline & \multicolumn{3}{|c|}{ Lagged IV } & \multicolumn{3}{|c|}{ Lagged DV } \\
\hline & $(1)$ & $(2)$ & (3) & $(4)$ & (5) & (6) \\
\hline Cellphone Coverage & $\begin{array}{c}-0.015^{* *} \\
(0.006)\end{array}$ & $\begin{array}{c}-0.013^{* *} \\
(0.005)\end{array}$ & $\begin{array}{l}-0.005 \\
(0.010)\end{array}$ & $\begin{array}{c}0.006 \\
(0.006)\end{array}$ & $\begin{array}{c}0.003 \\
(0.007)\end{array}$ & $\begin{array}{c}0.005 \\
(0.008)\end{array}$ \\
\hline Observations & 960 & 960 & 960 & 767 & 767 & 767 \\
\hline$R^{2}$ & 0.33 & 0.35 & 0.63 & 0.64 & 0.66 & 0.70 \\
\hline Year FE & Yes & No & No & Yes & No & No \\
\hline Region $\times$ Year FE & No & Yes & Yes & No & Yes & Yes \\
\hline Const. vary slope & No & No & Yes & No & No & Yes \\
\hline
\end{tabular}

Notes: This table presents carry over analysis for presidential elections. Models (1)-(3) regress incumbent vote share (Panel A) or turnout (Panel B) on continuous cellphone coverage in the previous election year. Model (1) corresponds to the model specification expressed in equation 1. Model (2) uses equation 2, and model (3) corresponds to equation 3. Const. stands for constituency. All models have constituency fixed effects and do not include any additional control variables.

Robust standard errors are shown in parentheses: ${ }^{* * *} p<0.01{ }^{* *} p<0.05 ;{ }^{*} p<0.1$.

Data source: Electoral Commission of Ghana. 
Table SI-8: Parlianentary Election Carry-over Analysis

\begin{tabular}{lcccccccc}
\hline Panel A: Incumbent Vote Share in Parliamentary election \\
\hline & \multicolumn{3}{c}{ Lagged IV } & & \multicolumn{3}{c}{ Lagged DV } \\
\cline { 2 - 3 } \cline { 7 - 8 } & $(1)$ & $(2)$ & $(3)$ & & $(4)$ & $(5)$ & $(6)$ \\
\hline Cellphone Coverage & 0.001 & 0.003 & -0.002 & -0.014 & -0.007 & 0.006 \\
& $(0.005)$ & $(0.005)$ & $(0.007)$ & & $(0.011)$ & $(0.012)$ & $(0.018)$ \\
\hline Observations & 972 & 972 & 972 & & 775 & 775 & 775 \\
$R^{2}$ & 0.77 & 0.80 & 0.86 & & 0.73 & 0.75 & 0.85 \\
\hline \hline
\end{tabular}

\begin{tabular}{lcccccccc}
\hline \hline Panel B: Turnout in Parliamentary election & & & \multicolumn{3}{c}{ Lagged DV } \\
\cline { 2 - 3 } \cline { 7 - 8 } & $(1)$ & $(2)$ & $(3)$ & & $(4)$ & $(5)$ & $(6)$ \\
\hline Cellphone Coverage & -0.007 & -0.005 & 0.007 & & $0.009^{*}$ & 0.007 & 0.007 \\
& $(0.006)$ & $(0.004)$ & $(0.009)$ & & $(0.005)$ & $(0.005)$ & $(0.007)$ \\
\hline Observations & 972 & 972 & 972 & & 776 & 776 & 776 \\
$R^{2}$ & 0.35 & 0.37 & 0.68 & & 0.83 & 0.85 & 0.90 \\
Year FE & Yes & No & No & & Yes & No & No \\
Region $\times$ Year FE & No & Yes & Yes & & No & Yes & Yes \\
Const. vary slope & No & No & Yes & & No & No & Yes \\
\hline
\end{tabular}

Notes: This table presents carry over analysis for parliamentary election. Models (1)-(3) regress incumbent vote share (Panel A) or turnout (Panel B) on continuous cellphone coverage in previous election year. Models (4)-(6) regress elections results from 2 election cycles ago on current continuous coverage measure. Model (1) and model (4) correspond model specification expressed in equation 1. Model (2) and model (5) use equation 2, model (3) and (6) correspond to equation 3. Const. stands for constituency. All models have constituency fixed effects and constituency-level control variables.

Robust standard errors are shown in parentheses: ${ }^{* * *} p<0.01 ;{ }^{* *} p<0.05 ;{ }^{*} p<0.1$.

Data source: Electoral commision of Ghana. 


\section{E. Robustness of Election Outcome Analysis}

\section{E.1. Event study specifications}

In panel settings with staggered adoption and heterogeneous treatment effects, conventional two-way fixed effects are prone to producing biased estimates because they implicitly average over multiple difference-in-differences comparisons, including some where already treated units serve as controls for newly treated units (Goodman-Bacon, 2021). Many estimators that correct this bias have been proposed; we use the imputation or fixed effects counterfactual estimator (Borusyak, Jaravel, and Spiess, 2021; Liu, Wang, and Xu, 2021), which minimally departs from the two-way FE design by restricting to untreated periods in the estimation of the unit and time fixed effects. We report event study plots of imputation estimators on presidential and parliamentary turnout below. We find that the effects of coverage expansion on incumbent vote share are large and persistent for both presidential and parliamentary elections, and are negligible for turnout in both.

Figure SI-3: Event study plots 50\% cutoff

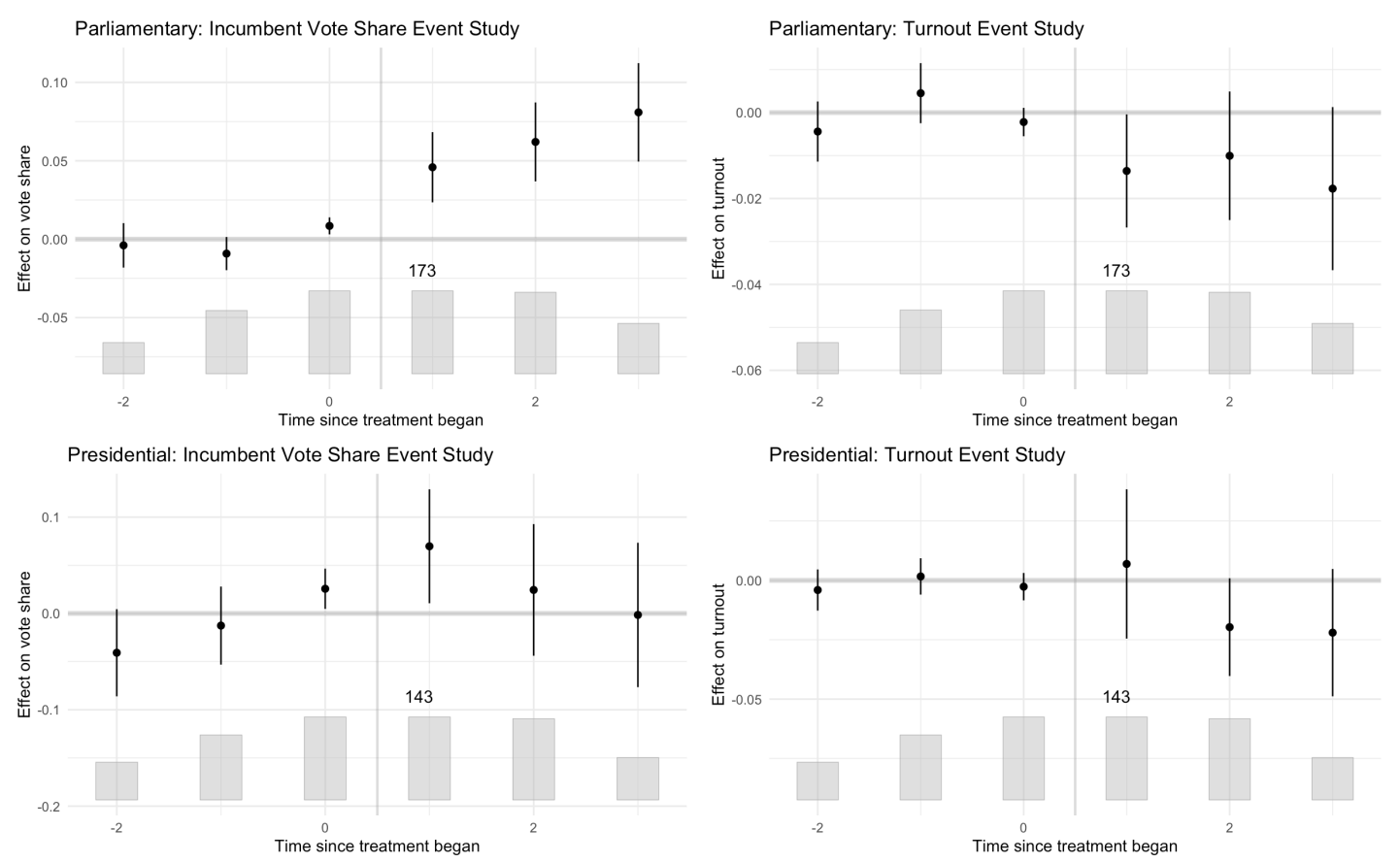

Notes: Event study plots from regression imputation, where treatment status is defined as the populationweighted coverage exceeding $50 \%$. Treatment is an absorbing state because mobile coverage is almost never withdrawn in the study period in Ghana. 


\section{E.2. Alternative specifications}

In this section, we demonstrate the robustness of the study's findings to various model specifications. First, we show that findings using a 50\% threshold to define a constituency as having heavy cellphone coverage are not sensitive to exclusion of flexible 2000 census controls interacted with election year dummies in both presidential elections (Table SI-9) and parliamentary elections (Table SI-10). Next, we test robustness to using a higher threshold (75\%) for defining heavy mobile coverage; we do so both with (Tables SI-11-SI-12) and without (Tables SI-13SI-14) our flexible 2000 census controls interacted with year dummies.

Table SI-9: Presidential Election Analysis with 50\% cutoff without controls

\begin{tabular}{|c|c|c|c|c|c|c|}
\hline \multicolumn{7}{|c|}{ Panel A: Incumbent Vote Share in Presidential election } \\
\hline & \multicolumn{3}{|c|}{ Discretized } & \multicolumn{3}{|c|}{ Continuous } \\
\hline & $(1)$ & $(2)$ & (3) & $(4)$ & (5) & (6) \\
\hline Cellphone Coverage & $\begin{array}{c}0.084^{* * *} \\
(0.025)\end{array}$ & $\begin{array}{c}0.067^{* * *} \\
(0.022)\end{array}$ & $\begin{array}{c}0.077^{* * *} \\
(0.028)\end{array}$ & $\begin{array}{c}0.070^{* * *} \\
(0.014)\end{array}$ & $\begin{array}{c}0.057^{* * *} \\
(0.014)\end{array}$ & $\begin{array}{c}0.068^{* * *} \\
(0.020)\end{array}$ \\
\hline Observations & 1153 & 1153 & 1153 & 1153 & 1153 & 1153 \\
\hline$R^{2}$ & 0.08 & 0.69 & 0.70 & 0.09 & 0.70 & 0.71 \\
\hline \multicolumn{7}{|c|}{ Panel B: Turnout in Presidential election } \\
\hline & \multicolumn{3}{|c|}{ Discretized } & \multicolumn{3}{|c|}{ Continuous } \\
\hline & (1) & $(2)$ & (3) & $(4)$ & (5) & (6) \\
\hline Cellphone Coverage & $\begin{array}{l}-0.016 \\
(0.023) \\
\end{array}$ & $\begin{array}{c}0.003 \\
(0.014) \\
\end{array}$ & $\begin{array}{c}0.006 \\
(0.016) \\
\end{array}$ & $\begin{array}{l}-0.014 \\
(0.017) \\
\end{array}$ & $\begin{array}{c}0.000 \\
(0.010) \\
\end{array}$ & $\begin{array}{c}0.004 \\
(0.012) \\
\end{array}$ \\
\hline Observations & 1153 & 1153 & 1153 & 1153 & 1153 & 1153 \\
\hline$R^{2}$ & 0.30 & 0.33 & 0.57 & 0.30 & 0.33 & 0.57 \\
\hline Year FE & Yes & No & No & Yes & No & No \\
\hline Region $\times$ Year FE & No & Yes & Yes & No & Yes & Yes \\
\hline Const. vary slope & No & No & Yes & No & No & Yes \\
\hline
\end{tabular}

Notes: This table presents coefficient estimates for presidential elections. The independent variable is dichotomous cellphone coverage measure in models (1)-(3), whereas continuous in models (4)-(6). Models (1) and (4) estimate equation 1. Models (2) and (5) estimate equation 2. And models (3) and (6) estimate equation 3. We do not include additional controls in any models. Const. stands for constituency. All models have constituency fixed effects and do not include any control variables.

Robust standard errors are shown in parentheses: ${ }^{* * *} p<0.01{ }^{* *} p<0.05 ;{ }^{*} p<0.1$.

Data source: Electoral commission of Ghana and GSMA. 
Table SI-10: Parliamentary Election Analysis with 50\% cutoff without controls

\begin{tabular}{|c|c|c|c|c|c|c|}
\hline \multicolumn{7}{|c|}{ Panel A: Incumbent Vote Share in Parliamentary election } \\
\hline & \multicolumn{3}{|c|}{ Discretized } & \multicolumn{3}{|c|}{ Continuous } \\
\hline & $(1)$ & $(2)$ & (3) & $(4)$ & (5) & (6) \\
\hline Cellphone Coverage & $\begin{array}{c}0.030^{* * *} \\
(0.008)\end{array}$ & $\begin{array}{c}0.027^{* * *} \\
(0.009)\end{array}$ & $\begin{array}{c}0.028^{* * *} \\
(0.011)\end{array}$ & $\begin{array}{c}0.026^{* * *} \\
(0.005)\end{array}$ & $\begin{array}{c}0.026^{* * *} \\
(0.005)\end{array}$ & $\begin{array}{c}0.029 * * * \\
(0.007)\end{array}$ \\
\hline $\begin{array}{l}\text { Observations } \\
R^{2}\end{array}$ & $\begin{array}{l}1167 \\
0.69\end{array}$ & $\begin{array}{l}1167 \\
0.74\end{array}$ & $\begin{array}{l}1167 \\
0.81\end{array}$ & $\begin{array}{l}1167 \\
0.70\end{array}$ & $\begin{array}{l}1167 \\
0.74\end{array}$ & $\begin{array}{l}1167 \\
0.81\end{array}$ \\
\hline \multicolumn{7}{|c|}{ Panel B: Turnout in Parliamentary election } \\
\hline & \multicolumn{3}{|c|}{ Discretized } & \multicolumn{3}{|c|}{ Continuous } \\
\hline & $(1)$ & $(2)$ & (3) & $(4)$ & $(5)$ & (6) \\
\hline Cellphone Coverage & $\begin{array}{l}-0.026 \\
(0.020)\end{array}$ & $\begin{array}{l}-0.006 \\
(0.008)\end{array}$ & $\begin{array}{l}-0.004 \\
(0.007)\end{array}$ & $\begin{array}{l}-0.014 \\
(0.017)\end{array}$ & $\begin{array}{c}0.000 \\
(0.010)\end{array}$ & $\begin{array}{c}0.004 \\
(0.012)\end{array}$ \\
\hline Observations & 1168 & 1168 & 1168 & 1153 & 1153 & 1153 \\
\hline$R^{2}$ & 0.31 & 0.34 & 0.62 & 0.30 & 0.33 & 0.57 \\
\hline Year FE & Yes & No & No & Yes & No & No \\
\hline Region $\times$ Year FE & No & Yes & Yes & No & Yes & Yes \\
\hline Const. vary slope & No & No & Yes & No & No & Yes \\
\hline
\end{tabular}

Notes: This table presents coefficient estimates for parliamentary elections. The independent variable is dichotomous cellphone coverage measure in models (1)-(3), whereas continuous in models (4)-(6). Models (1) and (4) estimate equation 1. Models (2) and (5) estimate equation 2. And models (3) and (6) estimate equation 3. We do not include additional controls in any models. Variants of these tables which include timevarying constituency controls appear in SI-16. Const. stands for constituency. All models have constituency fixed effects and do not include any control variables.

Robust standard errors are shown in parentheses: ${ }^{* * *} p<0.01{ }^{* *} p<0.05$; $^{*} p<0.1$.

Data source: Electoral commission of Ghana and GSMA. 
Table SI-11: Presidential Election Analysis with 75\% cutoff with controls

\begin{tabular}{|c|c|c|c|c|c|c|}
\hline \multicolumn{7}{|c|}{ Panel A: Incumbent Vote Share in Presidential election } \\
\hline & \multicolumn{3}{|c|}{ Discretized } & \multicolumn{3}{|c|}{ Continuous } \\
\hline & $(1)$ & $(2)$ & (3) & $(4)$ & (5) & $(6)$ \\
\hline Cellphone Coverage & $\begin{array}{c}0.019 \\
(0.022)\end{array}$ & $\begin{array}{c}0.018 \\
(0.018)\end{array}$ & $\begin{array}{c}0.017 \\
(0.025)\end{array}$ & $\begin{array}{c}0.036^{* * *} \\
(0.013)\end{array}$ & $\begin{array}{l}0.025^{* *} \\
(0.012)\end{array}$ & $\begin{array}{c}0.027 \\
(0.017)\end{array}$ \\
\hline $\begin{array}{l}\text { Observations } \\
R^{2}\end{array}$ & $\begin{array}{l}1153 \\
0.62\end{array}$ & $\begin{array}{l}1153 \\
0.82\end{array}$ & $\begin{array}{l}1153 \\
0.82\end{array}$ & $\begin{array}{l}1153 \\
0.62\end{array}$ & $\begin{array}{l}1153 \\
0.82\end{array}$ & $\begin{array}{l}1153 \\
0.82\end{array}$ \\
\hline \multicolumn{7}{|c|}{ Panel B: Turnout in Presidential election } \\
\hline & \multicolumn{3}{|c|}{ Discretized } & \multicolumn{3}{|c|}{ Continuous } \\
\hline & (1) & $(2)$ & (3) & $(4)$ & $(5)$ & $(6)$ \\
\hline Cellphone Coverage & $\begin{array}{c}0.010 \\
(0.018)\end{array}$ & $\begin{array}{c}0.013 \\
(0.019)\end{array}$ & $\begin{array}{c}0.022 \\
(0.025)\end{array}$ & $\begin{array}{c}0.008 \\
(0.013)\end{array}$ & $\begin{array}{c}0.013 \\
(0.014)\end{array}$ & $\begin{array}{c}0.016 \\
(0.017)\end{array}$ \\
\hline Observations & 1153 & 1153 & 1153 & 1153 & 1153 & 1153 \\
\hline$R^{2}$ & 0.31 & 0.34 & 0.58 & 0.31 & 0.34 & 0.58 \\
\hline Year FE & Yes & No & No & Yes & No & No \\
\hline Region $\times$ Year FE & No & Yes & Yes & No & Yes & Yes \\
\hline Const. vary slope & No & No & Yes & No & No & Yes \\
\hline
\end{tabular}

Notes: This table presents coefficient estimates for presidential elections. The independent variable is dichotomous cellphone coverage measure in models (1)-(3), whereas continuous in models (4)-(6). Models (1) and (4) estimate equation 1. Models (2) and (5) estimate equation 2. And models (3) and (6) estimate equation 3. We do not include additional controls in any models. Const. stands for constituency. All models have constituency fixed effects and do not include any control variables.

Robust standard errors are shown in parentheses: ${ }^{* * *} p<0.01 ;{ }^{* *} p<0.05 ;{ }^{*} p<0.1$.

Data source: Electoral commission of Ghana and GSMA. 
Table SI-12: Parliamentary Election Analysis with 75\% cutoff with controls

\begin{tabular}{|c|c|c|c|c|c|c|}
\hline \multicolumn{7}{|c|}{ Panel A: Incumbent Vote Share in Parliamentary election } \\
\hline & \multicolumn{3}{|c|}{ Discretized } & \multicolumn{3}{|c|}{ Continuous } \\
\hline & $(1)$ & $(2)$ & (3) & $(4)$ & (5) & $(6)$ \\
\hline Cellphone Coverage & $\begin{array}{c}0.029^{* * *} \\
(0.008)\end{array}$ & $\begin{array}{c}0.029^{* * *} \\
(0.009)\end{array}$ & $\begin{array}{c}0.028^{* * *} \\
(0.010)\end{array}$ & $\begin{array}{c}0.029^{* * *} \\
(0.006)\end{array}$ & $\begin{array}{c}0.030^{* * *} \\
(0.006)\end{array}$ & $\begin{array}{c}0.028^{* * *} \\
(0.007)\end{array}$ \\
\hline Observations & 1167 & 1167 & 1167 & 1167 & 1167 & 1167 \\
\hline$R^{2}$ & 0.73 & 0.76 & 0.82 & 0.73 & 0.76 & 0.82 \\
\hline \multicolumn{7}{|c|}{ Panel B: Turnout in Parliamentary election } \\
\hline & \multicolumn{3}{|c|}{ Discretized } & \multicolumn{3}{|c|}{ Continuous } \\
\hline & $(1)$ & $(2)$ & (3) & $(4)$ & $(5)$ & $(6)$ \\
\hline Cellphone Coverage & $\begin{array}{c}0.007 \\
(0.011)\end{array}$ & $\begin{array}{c}0.011 \\
(0.010)\end{array}$ & $\begin{array}{c}0.018 \\
(0.015)\end{array}$ & $\begin{array}{c}0.008 \\
(0.013)\end{array}$ & $\begin{array}{c}0.013 \\
(0.014)\end{array}$ & $\begin{array}{c}0.016 \\
(0.017)\end{array}$ \\
\hline Observations & 1168 & 1168 & 1168 & 1153 & 1153 & 1153 \\
\hline$R^{2}$ & 0.33 & 0.35 & 0.62 & 0.31 & 0.34 & 0.58 \\
\hline Year FE & Yes & No & No & Yes & No & No \\
\hline Region $\times$ Year FE & No & Yes & Yes & No & Yes & Yes \\
\hline Const. vary slope & No & No & Yes & No & No & Yes \\
\hline
\end{tabular}

Notes: This table presents coefficient estimates for parliamentary elections. The independent variable is dichotomous cellphone coverage measure in models (1)-(3), whereas continuous in models (4)-(6). Models (1) and (4) estimate equation 1. Models (2) and (5) estimate equation 2. And models (3) and (6) estimate equation 3. We do not include additional controls in any models. Const. stands for constituency. All models have constituency fixed effects and constituency-level control variables.

Robust standard errors are shown in parentheses: ${ }^{* * *} p<0.01 ;{ }^{* *} p<0.05 ;{ }^{*} p<0.1$.

Data source: Electoral commission of Ghana and GSMA. 
Table SI-13: Presidential Election Analysis with 75\% cutoff without controls

\begin{tabular}{|c|c|c|c|c|c|c|}
\hline \multicolumn{7}{|c|}{ Panel A: Incumbent Vote Share in Presidential election } \\
\hline & \multicolumn{3}{|c|}{ Discretized } & \multicolumn{3}{|c|}{ Continuous } \\
\hline & $(1)$ & $(2)$ & (3) & $(4)$ & $(5)$ & $(6)$ \\
\hline Cellphone Coverage & $\begin{array}{c}0.045^{*} \\
(0.025)\end{array}$ & $\begin{array}{c}0.063^{* * *} \\
(0.020)\end{array}$ & $\begin{array}{l}0.071^{* *} \\
(0.027)\end{array}$ & $\begin{array}{c}0.070^{* * *} \\
(0.014)\end{array}$ & $\begin{array}{c}0.057^{* * *} \\
(0.014)\end{array}$ & $\begin{array}{c}0.068^{* * *} \\
(0.020)\end{array}$ \\
\hline Observations & 1153 & 1153 & 1153 & 1153 & 1153 & 1153 \\
\hline$R^{2}$ & 0.07 & 0.69 & 0.70 & 0.09 & 0.70 & 0.71 \\
\hline \multicolumn{7}{|c|}{ Panel B: Turnout in Presidential election } \\
\hline & \multicolumn{3}{|c|}{ Discretized } & \multicolumn{3}{|c|}{ Continuous } \\
\hline & $(1)$ & $(2)$ & (3) & $(4)$ & $(5)$ & $(6)$ \\
\hline Cellphone Coverage & $\begin{array}{l}-0.019 \\
(0.025)\end{array}$ & $\begin{array}{l}-0.002 \\
(0.016)\end{array}$ & $\begin{array}{c}0.006 \\
(0.019)\end{array}$ & $\begin{array}{l}-0.014 \\
(0.017)\end{array}$ & $\begin{array}{c}0.000 \\
(0.010)\end{array}$ & $\begin{array}{c}0.004 \\
(0.012)\end{array}$ \\
\hline Observations & 1153 & 1153 & 1153 & 1153 & 1153 & 1153 \\
\hline$R^{2}$ & 0.30 & 0.33 & 0.57 & 0.30 & 0.33 & 0.57 \\
\hline Year FE & Yes & No & No & Yes & No & No \\
\hline Region $\times$ Year FE & No & Yes & Yes & No & Yes & Yes \\
\hline Const. vary slope & No & No & Yes & No & No & Yes \\
\hline
\end{tabular}

Notes: This table presents coefficient estimates for presidential elections. The independent variable is dichotomous cellphone coverage measure in models (1)-(3), whereas continuous in models (4)-(6). Models (1) and (4) estimate equation 1. Models (2) and (5) estimate equation 2. And models (3) and (6) estimate equation 3. We do not include additional controls in any models. Const. stands for constituency. All models have constituency fixed effects and do not include any control variables.

Robust standard errors are shown in parentheses: ${ }^{* * *} p<0.01 ;{ }^{* *} p<0.05 ;{ }^{*} p<0.1$.

Data source: Electoral commission of Ghana and GSMA. 
Table SI-14: Parliamentary Election Analysis with 75\% cutoff without controls

\begin{tabular}{|c|c|c|c|c|c|c|}
\hline \multicolumn{7}{|c|}{ Panel A: Incumbent Vote Share in Parliamentary election } \\
\hline & \multicolumn{3}{|c|}{ Discretized } & \multicolumn{3}{|c|}{ Continuous } \\
\hline & $(1)$ & $(2)$ & (3) & $(4)$ & $(5)$ & $(6)$ \\
\hline Cellphone Coverage & $\begin{array}{c}0.032^{* * *} \\
(0.008)\end{array}$ & $\begin{array}{c}0.028^{* * *} \\
(0.008)\end{array}$ & $\begin{array}{c}0.030^{* * *} \\
(0.009)\end{array}$ & $\begin{array}{c}0.026^{* * *} \\
(0.005)\end{array}$ & $\begin{array}{c}0.026^{* * *} \\
(0.005)\end{array}$ & $\begin{array}{c}0.029 * * * \\
(0.007)\end{array}$ \\
\hline Observations & 1167 & 1167 & 1167 & 1167 & 1167 & 1167 \\
\hline$R^{2}$ & 0.70 & 0.74 & 0.81 & 0.70 & 0.74 & 0.81 \\
\hline \multicolumn{7}{|c|}{ Panel B: Turnout in Parliamentary election } \\
\hline & \multicolumn{3}{|c|}{ Discretized } & \multicolumn{3}{|c|}{ Continuous } \\
\hline & (1) & (2) & (3) & $(4)$ & $(5)$ & (6) \\
\hline Cellphone Coverage & $\begin{array}{l}-0.024 \\
(0.022) \\
\end{array}$ & $\begin{array}{l}-0.006 \\
(0.007)\end{array}$ & $\begin{array}{c}0.000 \\
(0.007) \\
\end{array}$ & $\begin{array}{l}-0.014 \\
(0.017) \\
\end{array}$ & $\begin{array}{c}0.000 \\
(0.010) \\
\end{array}$ & $\begin{array}{c}0.004 \\
(0.012) \\
\end{array}$ \\
\hline Observations & 1168 & 1168 & 1168 & 1153 & 1153 & 1153 \\
\hline$R^{2}$ & 0.31 & 0.34 & 0.62 & 0.30 & 0.33 & 0.57 \\
\hline Year FE & Yes & No & No & Yes & No & No \\
\hline Region $\times$ Year FE & No & Yes & Yes & No & Yes & Yes \\
\hline Const. vary slope & No & No & Yes & No & No & Yes \\
\hline
\end{tabular}

Notes:This table presents coefficient estimates for parliamentary elections. The independent variable is dichotomous cellphone coverage measure in models (1)-(3), whereas continuous in models (4)-(6). Models (1) and (4) estimate equation 1. Models (2) and (5) estimate equation 2. And models (3) and (6) estimate equation 3. We do not include additional controls in any models. Const. stands for constituency. All models have constituency fixed effects and do not include any control variables.

Robust standard errors are shown in parentheses: ${ }^{* * *} p<0.01 ;{ }^{* *} p<0.05 ;{ }^{*} p<0.1$.

Data source: Electoral commission of Ghana and GSMA. 


\section{F. Night-Time Light Density}

Following Burke et al. (2021), we proxy local wealth with Night-time Light Density from a recently-published harmonized dataset ( $\mathrm{Li}$ et al., 2020). This dataset re-calibrated and integrated two sources of night-time light satelite data: the Defense Meteorological Satellite Program (DMSP)/Operational Linescan System (OLS) (1992-2013) and the Visible Infrared Imaging Radiometer Suite (VIIRS) (2012 - ). Night-time light density is recorded as a number ranging from 0 to 63 , with 30 arc-seconds' spatial resolution. We aggregated night-time light density in pixels up to the EA level using zonal statistics. Our main analysis from Table 3 aggregates the data to the EA level using the mean across pixels and normalizes this amount by EA population. Table SI-15 shows that these findings are not sensitive to using the sum rather than the mean to aggregate, or to whether or not we normalize by EA population.

\section{G. Census Wealth Index}

Table SI-16 shows that greater cellphone coverage predicts greater wealth. We follow a first differences model specification using changes over 2000-2010 in our continuous measure of cellphone coverage. The results hold whether we take as our unit of analysis the EA (columns 1-2) or the constituency (columns 3-4). The EA-level regression using first differences and our full set of controls (column 2) suggests that a 1 S.D. increase in cellphone coverage leads to a 0.071 S.D. increase in the wealth index value over this period, while the analogous constituencylevel regression yields a 0.33 S.D. increase in wealth. In all models, the coefficients on cellphone coverage are significant at the $1 \%$ level or higher. 
Table SI-15: Night-Time Light Density, other measures

\begin{tabular}{|c|c|c|c|c|c|c|}
\hline \multicolumn{7}{|c|}{ Panel A: NightTime Light Density Mean } \\
\hline & \multicolumn{3}{|c|}{ Discretized } & \multicolumn{3}{|c|}{ Continuous } \\
\hline & $(1)$ & $(2)$ & (3) & $(4)$ & (5) & $(6)$ \\
\hline Cellphone Coverage & $\begin{array}{c}0.180^{* * *} \\
(0.021)\end{array}$ & $\begin{array}{c}0.114^{* * *} \\
(0.020)\end{array}$ & $\begin{array}{l}-0.020 \\
(0.021)\end{array}$ & $\begin{array}{c}0.101^{* * *} \\
(0.011)\end{array}$ & $\begin{array}{c}0.067^{* * *} \\
(0.010)\end{array}$ & $\begin{array}{c}-0.008 \\
(0.011)\end{array}$ \\
\hline $\begin{array}{l}\text { Observations } \\
R^{2}\end{array}$ & $\begin{array}{c}141414 \\
0.95\end{array}$ & $\begin{array}{c}141414 \\
0.95\end{array}$ & $\begin{array}{c}141414 \\
0.98\end{array}$ & $\begin{array}{c}141414 \\
0.95\end{array}$ & $\begin{array}{c}141414 \\
0.95\end{array}$ & $\begin{array}{c}141414 \\
0.98\end{array}$ \\
\hline \multicolumn{7}{|c|}{ Panel B: NightTime Light Density Sum } \\
\hline & \multicolumn{3}{|c|}{ Discretized } & \multicolumn{3}{|c|}{ Continuous } \\
\hline & (1) & $(2)$ & (3) & $(4)$ & $(5)$ & (6) \\
\hline Cellphone Coverage & $\begin{array}{c}0.294^{* * *} \\
(0.023)\end{array}$ & $\begin{array}{c}0.214^{* * *} \\
(0.024)\end{array}$ & $\begin{array}{c}0.088^{* * *} \\
(0.024)\end{array}$ & $\begin{array}{c}0.146^{* * *} \\
(0.012)\end{array}$ & $\begin{array}{c}0.103^{* * *} \\
(0.012)\end{array}$ & $\begin{array}{c}0.039^{* * *} \\
(0.012)\end{array}$ \\
\hline $\begin{array}{l}\text { Observations } \\
R^{2}\end{array}$ & $\begin{array}{c}141414 \\
0.95\end{array}$ & $\begin{array}{c}141414 \\
0.95\end{array}$ & $\begin{array}{c}141414 \\
0.98\end{array}$ & $\begin{array}{c}141414 \\
0.95\end{array}$ & $\begin{array}{c}141414 \\
0.95\end{array}$ & $\begin{array}{c}141414 \\
0.98\end{array}$ \\
\hline \multicolumn{7}{|c|}{ Panel C: NightTime Light Density Sum Normalized by Population } \\
\hline & \multicolumn{3}{|c|}{ Discretized } & \multicolumn{3}{|c|}{ Continuous } \\
\hline & (1) & $(2)$ & (3) & $(4)$ & (5) & $(6)$ \\
\hline Cellphone Coverage & $\begin{array}{c}0.833^{* * *} \\
(0.064)\end{array}$ & $\begin{array}{c}0.537^{* * *} \\
(0.064)\end{array}$ & $\begin{array}{c}0.344^{* * *} \\
(0.079)\end{array}$ & $\begin{array}{c}0.419 * * * \\
(0.032)\end{array}$ & $\begin{array}{c}0.260^{* * *} \\
(0.031)\end{array}$ & $\begin{array}{c}0.160^{* * *} \\
(0.036)\end{array}$ \\
\hline Observations & 141414 & 141414 & 141414 & 141414 & 141414 & 141414 \\
\hline$R^{2}$ & 0.91 & 0.91 & 0.96 & 0.91 & 0.91 & 0.96 \\
\hline Year FE & Yes & No & No & Yes & No & No \\
\hline Region $\times$ Year FE & No & Yes & Yes & No & Yes & Yes \\
\hline EA vary slope & No & No & Yes & No & No & Yes \\
\hline
\end{tabular}

Notes: This table presents coefficient estimates for analysis using night-time light density data. The independent variable is dichotomous cellphone coverage measure in models (1)-(3), whereas continuous in models (4)-(6). Model (1) and model (4) follow model specification expressed in equation 1 . Model (2) and model (5) use equation 2, model (3) and (6) correspond to equation 3. All models have EA level fixed effects. Robust standard errors are shown in parentheses: ${ }^{* * *} p<0.01 ;{ }^{* *} p<0.05$; $^{*} p<0.1$. 
Table SI-16: Analysis of wealth data using 2000 and 2010 Census data

\begin{tabular}{lcccc}
\hline & $(1)$ & $(2)$ & $(3)$ & $(4)$ \\
\hline$\Delta$ Cellphone Coverage & $0.065^{* * *}$ & $0.071^{* * *}$ & $0.310^{* * *}$ & $0.329^{* * *}$ \\
& $(0.008)$ & $(0.008)$ & $(0.088)$ & $(0.090)$ \\
\hline Observations & 22421 & 22421 & 193 & 193 \\
$R^{2}$ & 0.034 & 0.044 & 0.248 & 0.254 \\
Administrative level & EA & EA & Constituency & Constituency \\
Controls & No & Yes & No & Yes \\
\hline
\end{tabular}

Notes: The unit of analysis for this table is EA the first two columns and constituency for the last two. All models are first-difference specifications, where changes in wealth index are regressed on changed in continuous cellphone coverage measure. Both the dependent variable and the independent variable are standardized to mean 0 and standard deviation being 1. All models include region fixed effects. Model 2 and model 4 include EA level and Constituency level controls separately. Control variables are the shares of the population from ethnic groups likely to support the NPP and the NDC based on 2000 Ghana census data.

Robust standard errors are shown in parentheses: ${ }^{* * *} p<0.01 ;{ }^{* *} p<0.05 ;{ }^{*} p<0.1$.

Data source: Ghana census 2000 and 2010. 


\section{H. Analysis of Mechanisms: Afrobarometer Analysis}

While in the main text (Table 4) we report only the effect of cellphone coverage on indices of interest (e.g., our wealth index, faith in the economy index, and government performance index), below we report in addition the results for each of those indices' constituent variables. 
Wealth Regression results are displayed in Table SI-17. Results for individual variables that composited the wealth index are also presented in the table. The effect of cellphone coverage on wealth is robust and comes from a number of different variables for which we identify statistically significant results: having enough food, enough medicine, and enough cash income.

Table SI-17: Afrobarometer: Wealth

\begin{tabular}{|c|c|c|c|c|c|c|c|c|c|c|c|c|}
\hline & \multicolumn{2}{|c|}{ Wealth index } & \multicolumn{2}{|c|}{ Enough food } & \multicolumn{2}{|c|}{ Enough water } & \multicolumn{2}{|c|}{ Enough medicine } & \multicolumn{2}{|c|}{ Enough cooking fuel } & \multicolumn{2}{|c|}{ Enough cash income } \\
\hline & $(1)$ & $(2)$ & (3) & $(4)$ & $(5)$ & (6) & $(7)$ & (8) & (9) & $(10)$ & $(11)$ & $(12)$ \\
\hline Cellphone Coverage & $\begin{array}{c}0.076^{* * *} \\
(0.015)\end{array}$ & $\begin{array}{c}0.071^{* * *} \\
(0.015)\end{array}$ & $\begin{array}{c}0.041^{* * *} \\
(0.015)\end{array}$ & $\begin{array}{c}0.043^{* * *} \\
(0.015)\end{array}$ & $\begin{array}{c}0.010 \\
(0.015)\end{array}$ & $\begin{array}{c}0.010 \\
(0.015)\end{array}$ & $\begin{array}{c}0.073^{* * *} \\
(0.015)\end{array}$ & $\begin{array}{c}0.070^{* * * *} \\
(0.015)\end{array}$ & $\begin{array}{c}0.020 \\
(0.018)\end{array}$ & $\begin{array}{c}0.017 \\
(0.018)\end{array}$ & $\begin{array}{c}0.026 \\
(0.016)\end{array}$ & $\begin{array}{c}0.021 \\
(0.016)\end{array}$ \\
\hline Observations & 7663 & 7663 & 9041 & 9041 & 9048 & 9048 & 9019 & 9019 & 7750 & 7750 & 7725 & 7725 \\
\hline$R^{2}$ & 0.49 & 0.50 & 0.04 & 0.04 & 0.04 & 0.05 & 0.08 & 0.08 & 0.02 & 0.02 & 0.10 & 0.11 \\
\hline Const. controls & No & Yes & No & Yes & No & Yes & No & Yes & No & Yes & No & Yes \\
\hline
\end{tabular}

Notes: This table presents coefficient estimates for wealth measures in Afrobarometer round 1 (1999) to round 6 (2015). Models (1), (2), (9) - (12) are missing round 1. The dependent variable in each model are listed in the top row. Detailed question wording, variables re-coding, and all individual-level controls that are included in all models are listed and explained in Table SI-3. Const. stands for constituency. All models include individual level fixed effects and do not have Region $\times$ Year fixed effects.

Robust standard errors are shown in parentheses: ${ }^{* * *} p<0.01 ;{ }^{* *} p<0.05 ;{ }^{*} p<0.1$.

Faith in the economy Table SI-18 shows that the positive effect of cellphone coverage on faith in the economy is driven mainly by improved positive perceptions of both current economic conditions and of whether economic policy benefits people.

Table SI-18: Afrobarometer: Faith in Economy

\begin{tabular}{|c|c|c|c|c|c|c|c|c|c|c|c|c|}
\hline & \multicolumn{2}{|c|}{ Faith in economy index } & \multicolumn{2}{|c|}{ Current economy condition } & \multicolumn{2}{|c|}{ Past economy condition } & \multicolumn{2}{|c|}{ Economic policy benefits people } & \multicolumn{2}{|c|}{ More jobs created } & \multicolumn{2}{|c|}{ Economy improved } \\
\hline & (1) & (2) & (3) & (4) & (5) & (6) & (7) & (8) & (9) & (10) & (11) & (12) \\
\hline Cellphone Coverage & $\begin{array}{c}0.062^{* * *} \\
(0.021)\end{array}$ & $\begin{array}{c}0.055^{* * *} \\
(0.021)\end{array}$ & $\begin{array}{c}0.000 \\
(0.017)\end{array}$ & $\begin{array}{c}0.002 \\
(0.017)\end{array}$ & $\begin{array}{c}0.008 \\
(0.017)\end{array}$ & $\begin{array}{c}0.007 \\
(0.017)\end{array}$ & $\begin{array}{l}0.053^{* *} \\
(0.021)\end{array}$ & $\begin{array}{l}0.049^{* *} \\
(0.022)\end{array}$ & $\begin{array}{l}-0.021 \\
(0.014)\end{array}$ & $\begin{array}{l}-0.022 \\
(0.014)\end{array}$ & $\begin{array}{c}0.013 \\
(0.015)\end{array}$ & $\begin{array}{c}0.015 \\
(0.015)\end{array}$ \\
\hline Observations & 2789 & 2789 & 5443 & 5443 & 5426 & 5426 & 3033 & 3033 & 8757 & 8757 & 7521 & 7521 \\
\hline$R^{2}$ & 0.12 & 0.13 & 0.05 & 0.05 & 0.04 & 0.04 & 0.04 & 0.04 & 0.10 & 0.10 & 0.17 & 0.17 \\
\hline Const. controls & No & Yes & No & Yes & No & Yes & No & Yes & No & Yes & No & Yes \\
\hline
\end{tabular}

Notes: This table presents coefficient estimates for respondents' faith in economy. The dependent variables in each model are listed in the top row. Detailed question wording, variables re-coding, and all individual-level controls that are included in all models are listed and explained in Table SI-3. Const. stands for constituency. All models include individual level fixed effects and do not have Region $\times$ Year fixed effects.

Robust standard errors are shown in parentheses: ${ }^{* * *} p<0.01 ;{ }^{* *} p<0.05 ;{ }^{*} p<0.1$.

Government performance We did not find evidence of cellphone coverage improving people's perceptions of government performance. These generally null effects are reported in Table SI-19. 
Table SI-19: Afrobarometer: Government Performance

\begin{tabular}{|c|c|c|c|c|c|c|c|c|c|c|c|c|c|}
\hline & \multicolumn{3}{|c|}{ Government performance index } & \multicolumn{2}{|c|}{ Economy improved } & \multicolumn{2}{|c|}{ More jobs created } & \multicolumn{2}{|c|}{ Price Stabilized } & \multicolumn{2}{|c|}{ Inequality reduced } & \multicolumn{2}{|c|}{ Crimes reduced } \\
\hline & (1) & \multicolumn{2}{|c|}{ (2) } & (3) & $(4)$ & (5) & (6) & (7) & (8) & (9) & (10) & (11) & (12) \\
\hline Cellphone Coverage & $\begin{array}{l}-0.018 \\
(0.016)\end{array}$ & \multicolumn{2}{|c|}{$\begin{array}{l}-0.016 \\
(0.016)\end{array}$} & $\begin{array}{c}0.013 \\
(0.015)\end{array}$ & $\begin{array}{c}0.015 \\
(0.015)\end{array}$ & $\begin{array}{l}-0.021 \\
(0.014)\end{array}$ & $\begin{array}{l}-0.022 \\
(0.014)\end{array}$ & $\begin{array}{l}-0.013 \\
(0.014)\end{array}$ & $\begin{array}{l}-0.013 \\
(0.014)\end{array}$ & $\begin{array}{l}-0.007 \\
(0.015)\end{array}$ & $\begin{array}{l}-0.006 \\
(0.015)\end{array}$ & $\begin{array}{c}0.022 \\
(0.014)\end{array}$ & $\begin{array}{c}0.021 \\
(0.014)\end{array}$ \\
\hline Observations & 4521 & \multicolumn{2}{|c|}{4521} & 7521 & 7521 & 8757 & 8757 & 8862 & 8862 & 8575 & 8575 & 8808 & 8808 \\
\hline \multirow[t]{3}{*}{$R^{2}$} & 0.09 & \multicolumn{2}{|c|}{0.09} & 0.17 & 0.17 & 0.10 & 0.10 & 0.11 & 0.11 & 0.05 & 0.05 & 0.07 & 0.07 \\
\hline & \multicolumn{2}{|c|}{ Better Health Services } & \multicolumn{2}{|c|}{ Better education } & \multicolumn{2}{|c|}{ Better water condition } & \multicolumn{2}{|c|}{ Better food provision } & \multicolumn{2}{|c|}{ Less corruption } & \multicolumn{3}{|c|}{ HIV/AIDS issue improved } \\
\hline & (1) & (2) & (3) & (4) & (5) & (6) & (7) & (8) & (9) & (10) & (11) & & 12) \\
\hline Cellphone Coverage & $\begin{array}{l}-0.015 \\
(0.013)\end{array}$ & $\begin{array}{l}-0.014 \\
(0.013)\end{array}$ & $\begin{array}{c}-0.024^{*} \\
(0.013)\end{array}$ & $\begin{array}{l}-0.023^{*} \\
(0.013)\end{array}$ & $\begin{array}{c}0.000 \\
(0.016)\end{array}$ & $\begin{array}{c}0.000 \\
(0.016)\end{array}$ & $\begin{array}{l}-0.014 \\
(0.016)\end{array}$ & $\begin{array}{l}-0.012 \\
(0.016)\end{array}$ & $\begin{array}{c}-0.041^{* * *} \\
(0.014)\end{array}$ & $\begin{array}{c}-0.039^{* * *} \\
(0.014)\end{array}$ & $\begin{array}{r}-0.018 \\
(0.017)\end{array}$ & & 0.016 \\
\hline Observ & 8861 & 8861 & 8865 & 8865 & 7592 & 7592 & 7460 & 7460 & 8482 & 8482 & 5110 & & 110 \\
\hline$R^{2}$ & 0.15 & 0.15 & 0.15 & 0.15 & 0.09 & 0.09 & 0.13 & 0.13 & 0.15 & 0.16 & 0.04 & & .04 \\
\hline Const. controls & No & Yes & No & Yes & No & Yes & No & Yes & No & Yes & No & & Yes \\
\hline
\end{tabular}

Notes: This table presents coefficient estimates for respondents' perception of government performance from Afrobarometer. The dependent variable in each model is listed in the top row. Detailed question wording, variables re-coding, and all individual-level controls that are included in all models are listed and explained in Table SI-3. Const. stands for constituency. All models include individual level fixed effects and do not have Region $\times$ Year fixed effects.

Robust standard errors are shown in parentheses: ${ }^{* * *} p<0.01{ }^{* *} p<0.05 ;{ }^{*} p<0.1$.

Political knowledge Further, we explored the possibility that political knowledge got expanded as the result of increasing cellphone coverage, which could very likely alter election outcomes. We were not able to use two-period time trend models for all dependent variables except for one variable: "can name MP," which appeared in both round 3 and round 4. Other questions related to political knowledge varied a lot in different rounds. Therefore, we applied cross-sectional regression with pre-treatment covariates on some knowledge questions that only appear in a single round-either round 3 (2005) or round 4 (2008).

$$
y_{i}=\tau \text { Coverage }_{i}+\zeta \boldsymbol{Z}_{i}^{\prime}+\varepsilon_{i}
$$

Table SI-20: Afrobarometer: Political Knowledge

\begin{tabular}{|c|c|c|c|c|c|c|c|}
\hline & MP & Minister of Finance & Local gov. councilor & Deputy president & Party with the most seats & Term limits knowledge & Const. laaw knowledge \\
\hline & (1) & (2) & (3) & (4) & (5) & (6) & (7) \\
\hline Cellphone Coverage & $\begin{array}{c}0.027 \\
(0.025)\end{array}$ & $\begin{array}{c}0.021 \\
(0.038)\end{array}$ & $\begin{array}{l}-0.012 \\
(0.033)\end{array}$ & $\begin{array}{c}0.053 \\
(0.034)\end{array}$ & $\begin{array}{c}0.045 \\
(0.034)\end{array}$ & $\begin{array}{l}0.063^{*} \\
(0.035)\end{array}$ & $\begin{array}{c}0.000 \\
(0.034)\end{array}$ \\
\hline Observations & 2141 & 1083 & 1058 & 1058 & 1058 & 1058 & 1058 \\
\hline$R^{2}$ & 0.13 & 0.15 & 0.16 & 0.16 & 0.20 & 0.15 & 0.08 \\
\hline Const. controls & No & Yes & No & Yes & No & Yes & No \\
\hline
\end{tabular}

Notes: This table presents coefficient estimates for respondents' political knowledge in Afrobarometer. The dependent variable in each model is listed in the top row, indicating if the respondent can name: MP, local gov. councilor, deputy president, party with the most parliamentary seats, term limits, constitutional law. All models use a cross-sectional specification as shown in Eqn 4 except for model (1) which include two rounds. Detailed question wording, variables re-coding, and all individual-level controls that are included in all models are listed and explained in Table SI-3. Const. stands for constituency. All models include individual level fixed effects and do not have Region $\times$ Year fixed effects.

Robust standard errors are shown in parentheses: ${ }^{* * *} p<0.01$; $^{* *} p<0.05 ;{ }^{*} p<0.1$. 
Vote buying Vote buying is another key outcome that would be influential to electoral results. This question was only asked in rounds 3 (2005) and round 5 (2012). Using these two rounds, we applied the two-period time trend model as described above. Results presented in Table 4 suggest that cellphone coverage decreases the incidence of vote-buying.

\section{References}

Borusyak, Kirill, Xavier Jaravel, and Jann Spiess (2021). "Revisiting Event Study Designs: Robust and Efficient Estimation". DOI: 10.48550/ARXIV.2108.12419.

Burke, Marshall et al. (2021). "Using satellite imagery to understand and promote sustainable development". Science 371.6535, eabe8628.

Buys, Piet et al. (2009). "Determinants of a digital divide in Sub-Saharan Africa: A spatial econometric analysis of cell phone coverage". World Development 37.9, pp. 1494-1505.

Cattaneo, Matias D et al. (2021). “On binscatter". arXiv preprint arXiv:1902.09608.

Christensen, Darin and Francisco Garfias (2018). "Can you hear me now? How communication technology affects protest and repression". Quarterly journal of political science 13.1, p. 89.

Goodman-Bacon, Andrew (2021). “Difference-in-differences with variation in treatment timing". Journal of Econometrics 225.2, pp. 254-277.

GSMA (2019). “Mobile coverage explorer". CollinsBartholomew. URL https:/ /www. collinsbartholomew. com/mobile-coverage-maps/mobile-coverage-explorer/ (accessed 5.18. 20).

Li, Xuecao et al. (2020). "A harmonized global nighttime light dataset 1992-2018". Scientific data 7.1, pp. 1-9.

Liu, Licheng, Ye Wang, and Yiqing Xu (2021). "A practical guide to counterfactual estimators for causal inference with time-series cross-sectional data". arXiv preprint arXiv:2107.00856.

Manacorda, Marco and Andrea Tesei (2020). "Liberation technology: Mobile phones and political mobilization in Africa". Econometrica 88.2, pp. 533-567.

Pierskalla, Jan H and Florian M Hollenbach (2013). “Technology and collective action: The effect of cell phone coverage on political violence in Africa". American Political Science Review 107.2, pp. 207-224. 